\title{
PTEN enhances nasal epithelial cell resistance to TNF $\alpha$-induced inflammatory injury by limiting mitophagy via repression of the TLR4-JNK-Bnip3 pathway
}

\author{
MENG LI ${ }^{1}$, XIANG YANG ${ }^{2}$ and SHOUCHUAN WANG ${ }^{3}$ \\ Departments of ${ }^{1}$ Chinese Medicine and ${ }^{2}$ Cardiac Surgery, \\ Children's Hospital Affiliated to Capital Institute of Pediatrics, Beijing 100020; \\ ${ }^{3}$ Department of Chinese Medicine, Nanjing University of Chinese Medicine, Nanjing, Jiangsu 210029, P.R. China
}

Received January 6, 2018; Accepted May 23, 2018

DOI: $10.3892 / \mathrm{mmr} .2018 .9264$

\begin{abstract}
Nasal epithelial cell inflammatory injury is associated with chronic obstructive pulmonary disease development. However, the mechanism by which inflammation triggers nasal epithelial cell damage remains unclear. In the present study, tumor necrosis factor (TNF) $\alpha$ was used to induce an inflammatory injury and explore the underlying pathogenesis for nasal epithelial cell apoptosis in vitro, with a focus on mitochondrial homeostasis. Then, cellular apoptosis was detected via a terminal deoxynucleotidyl-transferase-mediated dUTP nick end labeling assay and western blotting. Mitochondrial function was evaluated via JC-1 staining, mPTP opening measurement and western blotting. The results demonstrated that $\mathrm{TNF} \alpha$ treatment induced nasal epithelial cell apoptosis, proliferation arrest and migration inhibition via downregulating phosphatase and tensin homolog (PTEN) levels. Increased PTEN expression was associated with reduce Toll-like receptor (TLR)4-c-Jun kinase (JNK)-Bcl2-interacting protein 3 (Bnip3) pathway signaling, leading to reductions in mitophagy activity. Excessive mitophagy resulted in ATP deficiencies, mitochondrial dysfunction, caspase-9 activation and cellular apoptosis. By contrast, PTEN overexpression in nasal epithelial cells alleviated the mitochondrial damage and cellular apoptosis via inhibiting the TLR4-JNK-Bnip3 pathway, favoring the survival of nasal epithelial cells under inflammatory injury. Therefore, this data uncovered a potential molecular basis for nasal epithelial cell apoptosis in response to inflammatory injury, and PTEN was identified as the endogenous defender of nasal epithelial cell survival via controlling lethal mitophagy
\end{abstract}

Correspondence to: Professor Meng Li, Department of Chinese Medicine, Children's Hospital Affiliated to Capital Institute of Pediatrics, 2 Yabao Road, Chaoyang, Beijing 100020, P.R. China E-mail: xiaoci1987124@126.com

Key words: inflammatory injury, nasal epithelial cell, apoptosis, phosphatase and tensin homolog, mitophagy, Toll-like receptor 4/c-Jun kinase/Bcl2-interacting protein 3 pathway by inhibiting the TLR4-JNK-Bnip3 pathway, suggesting that this pathway may be a potential target for clinically treating chronic nasal and sinus inflammatory injury.

\section{Introduction}

Chronic nasal and sinus inflammatory injury is closely associated with the development of chronic obstructive pulmonary disease (COPD) (1). Furthermore, clinical studies have also confirmed that patients with nasal and sinus inflammation have a greater risk of cardiovascular disease due to chronic airway remodeling and airflow limitations (2). Additionally, anti-inflammatory therapy has been demonstrated to alleviate upper airway symptoms such as rhinorrhea, nasal obstruction and sneezing in patients with COPD $(3,4)$. Thus, this information illustrates that sinonasal inflammation is the pathogenesis responsible for airway damage and COPD development. Accordingly, reducing the excessive inflammatory response and increasing the resistance of nasal epithelial cells to inflammation-induced damage are vital for slowing or preventing COPD progression.

In response to inflammatory injury, Toll-like receptors (TLRs), particularly TLR4, have been demonstrated as the primary downstream effectors of inflammatory responses $(5,6)$. Increased TLR4 expression induces cellular oxidative stress and calcium overload, leading to nasal epithelial cell death (7). Subsequently, TLR4 also promotes transforming growth factor- $\beta$ and matrix metalloproteinase 9 expression $(8,9)$, the regulators of tissue fibrosis, resulting in airway remodeling. Notably, TLR4 inhibitors exert beneficial effects on nasal epithelial cells under chronic inflammatory injury (10). This evidence indicates that TLR4 modulation is vital for preserving nasal epithelial cell function and reducing airway damage. However, the underlying mechanism by which TLR4 induces nasal epithelial cell damage remains unknown.

Previous studies have demonstrated that mitochondria are the primary target of inflammatory injury $(11,12)$. Activated TLR4, induced by the inflammatory response, promotes mitochondrial membrane potential collapse and mitochondrial energy disorder $(10,13)$. Furthermore, the damaged mitochondria ultimately induce caspase-9-associated apoptotic 
signaling $(14,15)$, leading to nasal epithelial cell death. Recently, mitophagy has become a research hotspot (16). Mitophagy, a selective type of autophagy for mitochondria, can remove mitochondria via lysosomal degradation (17). Moderate mitophagy has been demonstrated to reduce cellular apoptosis via the timely removal of damaged mitochondria $(18,19)$. By contrast, excessive mitophagy aggravates the cellular damage via aberrant mitochondrial degradation $(20,21)$. Previous studies have demonstrated that mitophagy contributes to endothelial cell apoptosis in ischemia/reperfusion-triggered inflammatory injury $(22,23)$. Furthermore, in cancer cells, mitophagy activation impairs tumor migration via reducing energy production and generating reactive oxygen species (ROS)-associated oxidative stress (24). Based on this knowledge, it is important to investigate whether mitophagy is involved in inflammatory injury in nasal epithelial cells.

In addition to mitophagy, phosphatase and tensin homolog (PTEN) is the intrinsic defender of nasal and sinus inflammatory injury $(25,26)$. PTEN functions as a tumor suppressor involving in the regulation of the cell growth and differentiation (27). Previous studies have demonstrated that PTEN upregulation provides a survival advantage to nasal epithelial cells in asthma (28). Furthermore, pharmacological PTEN inhibition amplifies acute kidney injury (29,30), regulates inflammation-induced migration of myelocytes in zebrafish (31), and impacts nuclear factor- $\kappa \mathrm{B}$ inflammatory pathways (32). This information confirms that PTEN is associated with inflammatory response. Notably, whether PTEN can regulate TLR4-associated inflammatory injury in nasal epithelial cells via mitophagy is unknown. The aim of the present study was to investigate the role of PTEN in inflammatory-associated injury of nasal epithelial cells, with a focus on mitophagy and the TLR4-c-Jun kinase (JNK)-Bcl2-interacting protein 3 (Bnip3) signaling pathway.

\section{Materials and methods}

Cell experiments and treatment. The human nasal epithelial cell line (RPMI 2650) used in the present study was purchased from the Chinese Academy of Sciences Cell Bank (Shanghai, China). The cells were incubated with L-Dulbecco's modified Eagle's medium (Gibco; Thermo Fisher Scientific, Inc., Waltham, MA, USA) with $10 \%$ fetal bovine serum (FBS; Gibco; Thermo Fisher Scientific, Inc.) at $37^{\circ} \mathrm{C} / 5 \% \mathrm{CO}_{2}$. TNF $\alpha(0-20 \mathrm{ng} / \mathrm{ml}$; Selleck Chemicals, Houston, TX, USA) was added into the medium for $12 \mathrm{~h}$ to induce inflammatory injury in vitro according to a previous study (33). To inhibit mitophagy, 3-methyladenine (3-MA; $10 \mathrm{mM}$, Selleck Chemicals) was applied for $\sim 45 \mathrm{~min}$ in nasal epithelial cell line $\left(1 \times 10^{6}\right)(34)$. To activate mitophagy, carbonyl cyanide-p-trifluoromethoxyphenylhydrazone (FCCP; $5 \mu \mathrm{M}$, Selleck Chemicals) was applied for $\sim 30 \mathrm{~min}$ in nasal epithelial cell line $\left(1 \times 10^{6}\right)$.

Immunofluorescence staining. The samples were first washed with cold phosphate-buffered saline (PBS), fixed with $4 \%$ paraformaldehyde for $30 \mathrm{~min}$ at room temperature, and then permeabilized in $0.1 \%$ Triton $\mathrm{X}-100$ for $10 \mathrm{~min}$ at $4^{\circ} \mathrm{C}$. Subsequently, $10 \%$ goat serum albumin (Invitrogen; Thermo Fisher Scientific, Inc., Waltham, MA, USA) was used to block the samples for $1 \mathrm{~h}$ at room temperature. Subsequently, samples were incubated with primary antibodies overnight at $4^{\circ} \mathrm{C}(35)$. After three rinses in PBS, secondary antibodies (Alexa Fluor 488 donkey anti-rabbit secondary antibodies (1:1,000; cat. no. A-21206; Invitrogen; Thermo Fisher Scientific, Inc.) were added to the samples for $1 \mathrm{~h}$ at room temperature (34). The following primary antibodies were used in the present study: PTEN (1:5,000; cat. no. ab31392), mitochondrial import receptor subunit TOM20 homolog (mitochondrial marker; 1:1,000; cat. no. ab78547), lysosome-associated membrane glycoprotein 1 (lysosome marker, 1:1,000; cat. no. ab24170), and HtrA serine peptidase 2 (1:500; HtrA2/Omi; cat. no. ab32092; all Abcam, Cambridge, UK). Images were observed with an inverted microscope (magnification, x40; BX51; Olympus Corporation, Tokyo, Japan). Image-Pro Plus 4.5 software (Media Cybernetics, Inc., Rockville, MD, USA) was used to quantify the immunofluorescence according to a previous study (36). Mitophagy is the result of fusion between mitochondria and lysosome. The green mitochondria locate with red lysosome would generate the orange mitophagy. Then, the number of orange dot was measured to quantify the number of mitophagy (37).

Western blotting. Cells were lysed in Laemmli Sample Buffer (Bio-Rad Laboratories, Inc., Hercules, CA, USA). Proteins were isolated and concentrations were determined using the Bicinchoninic Acid Protein Assay kit (Thermo Fisher Scientific, Inc.) according to the manufacturer's protocol (38). Total protein (40-60 $\mu \mathrm{g}$ ) was separated by $12-15 \%$ SDS-PAGE. Following electrophoresis, the proteins were transferred to a polyvinylidene fluoride membrane (Roche Applied Science, Penzberg, Germany) (39). Bands were detected using an enhanced chemiluminescence substrate (Applygen Technologies, Inc., Beijing, China). Membranes were blocked with 5\% nonfat dried milk in Tris-buffered saline containing $0.05 \%$ Tween-20 (TBST) for $2 \mathrm{~h}$ at room temperature. Band intensities were normalized to the respective internal standard signal intensity ( $\beta$-actin; $1: 2,000$; cat. no. ab8226 and GAPDH; 1:2,000; cat. no. ab9485; both Abcam) (40). The experiment was repeated three times. The primary antibodies used in the study were as follows: Sequestome-1 (p62; 1:1,000; cat. no. ab56416), Bnip3 (1:1,000; cat. no. ab109362), Bcl-associated X protein (Bax; 1:1,000; cat. no. ab32503; all Abcam), pro-caspase-3 (1:1,000; cat. no. 9662; Cell Signaling Technology, Inc., Danvers, MA, USA), caspase-9 (1:1,000; cat. no. ab32539; Abcam), Beclin-1 (1:1,000; cat. no. 3495), cleaved caspase-3 (1:1,000; cat. no. 9664; both Cell Signaling Technology, Inc.), TLR4 (1:1,000; cat. no. ab13556; Abcam), microtubule-associated protein light chain (LC)3II (1:1,000; cat. no. 3868; Cell Signaling Technology, Inc.), PTEN (1:1,000; cat. no. ab31392; Abcam), Bcl2 (1:1,000; cat. no. 3498; Cell Signaling Technology, Inc.), Bad (1:1,000; cat. no. ab90435), CXCR4 (1:1,000; cat. no. ab1670), CXCR7 (1:1,000; cat. no. ab38089; all Abcam), t-JNK (1:1,000; cat. no. 4672), p-JNK (1:1,000; cat. no. 9251) and autophagy protein 5 (Atg5; 1:1,000; cat. no. 12994; all Cell Signaling Technology, Inc.). The second antibodies used in the present study were as follows: Horseradish peroxidase-conjugated secondary antibodies (1:2,000; cat. nos. 7076 and 7074; Cell Signaling Technology, Inc.) for $1 \mathrm{~h}$ at room temperature. Band intensities were normalized to the respective internal 
standard signal intensity ( $\beta$-actin or GAPDH) using Quantity One Software (version 4.6.2; Bio-Rad Laboratories, Inc.).

Flow cytometric analysis of cellular ROS. To observe the cellular ROS levels, flow cytometric analysis was used. In brief, nasal epithelial cell $\left(1 \times 10^{6}\right)$ was washed with PBS, and the ROS probe $(5 \mathrm{mg} / \mathrm{ml}$; dihydroethidium; Molecular Probes; Thermo Fisher Scientific, Inc.) was incubated with the cells for $\sim 30 \mathrm{~min}$ at $37^{\circ} \mathrm{C}$ in the dark. Subsequently, the cells were washed with PBS to remove the ROS probe. Following this, the cells were digested with $0.25 \%$ pancreatin (41). Following resuspension in PBS, the cells were immediately analyzed using a flow cytometer (Sysmex Partec $\mathrm{GmbH}$, Görlitz, Germany). The quantification of cellular ROS was performed per 10,000 cells in each group, and the data were analyzed with Flowmax software (Sysmex Partec, Version 2.3, Germany) (42).

Mitochondria permeability transition pore (mPTP) opening assay and ATP production. MPTP opening is an early event in mitochondrial apoptosis (43). In the present study, mPTP opening was measured via tetramethylrhodamine ethyl ester fluorescence. The nasal epithelial cell $\left(1 \times 10^{6}\right)$ was washed with PBS approximately three times and then were loaded with tetramethylrhodamine ethyl ester. The baseline fluorescence of tetramethylrhodamine ethyl ester was recorded. Following $30 \mathrm{~min}$, the tetramethylrhodamine ethyl ester fluorescence was recorded again. According to a previous study (44), the mPTP opening rate was determined when the fluorescence intensity was decreased to half of the baseline fluorescence intensity. ATP production was detected to reflect mitochondrial function. First, the samples were washed with cold PBS approximately three times. Subsequently, the samples were lysed in Laemmli Sample Buffer, and the luciferase-based ATP assay kit (cat. no. S0026B, Beyotime Institute of Biotechnology, Haimen, China) was used. ATP production was measured via a microplate reader (45).

JC-1 staining and isolation of mitochondrial-enriched fraction. The JC-1 assay was used to investigate mitochondrial potential. Briefly, the MitoProbe ${ }^{\mathrm{TM}} \mathrm{JC}-1$ assay kit (Thermo Fisher Scientific Inc.) was applied to cells $\left(1 \times 10^{6}\right)$ at $37^{\circ} \mathrm{C}$ in the dark for $15-20 \mathrm{~min}$. Subsequently, PBS was used to wash the cells three times. Finally, mitochondrial potential was determined using a fluorescence microscope and the images were captured (46). To isolate the mitochondrial fraction in order to analyze the expression associated with mitochondrial HtrA2/Omi, cells $\left(1 \times 10^{6}\right)$ were washed with cold PBS and incubated on ice in lysis buffer (Beyotime Institute of Biotechnology) for $30 \mathrm{~min}$. Then, mitochondria were isolated using a commercial kit (cat. no. C3601, Beyotime Institute of Biotechnology) according to the previous study (47).

RNA isolation and reverse transcription-quantitative polymerase chain reaction ( $R T-q P C R$ ). TRIzol reagent (Invitrogen; Thermo Fisher Scientific, Inc.) was used to isolate total RNA from cells (24). Subsequently, the Reverse Transcription kit (Kaneka Eurogentec S.A., Seraing, Belgium) was applied to transcribe RNA ( $1 \mu \mathrm{g}$ in each group) into cDNA at room temperature $\left(\sim 25^{\circ} \mathrm{C}\right)$ for $30 \mathrm{~min}$. The $\mathrm{qPCR}$ was performed with primers and matched probes from the Universal Fluorescence-labeled Probe Library (Roche Applied Science) using SYBR ${ }^{\mathrm{TM}}$ Green PCR Master Mix (Thermo Fisher Scientific, Inc.) (48). The primers used in the present study were as follows: PTEN forward, 5'-GACTGGCCCAGTGTT CTTCGCTTC-3' and reverse, 5'-GCTTCTGACAGAAGG AAAGCCAA-3'; and GAPDH forward, 5'-GCTACAGCT TCACCACCACA-3' and reverse, 5'-GCCATCTCTTGCTCG AAGTC-3'). The cycling conditions were as follows: $95^{\circ} \mathrm{C}$ for $8 \mathrm{~min}$, followed by 35 cycles of $95^{\circ} \mathrm{C}$ for $10 \mathrm{sec}$ and $72^{\circ} \mathrm{C}$ for $12 \mathrm{sec}$, for telomere PCR. Fold change of PTEN mRNA expression was normalized by GAPDH as an internal control.

RNA interference assay. In the present study, to inhibit TLR4 expression, small interference (si)RNA against TLR4 was used. The siRNA sequences were as follows: siRNA sense strand, 5'-GCTACTGTAGGAUAGTAU-3' and antisense strand, 3'-TCTTCUUAGCTGCATAAU-5'. The siRNA was designed and purchased from Yangzhou Ruibo Biotech Co., Ltd. (Yangzhou, China). To transfect the siRNA, Opti-Minimal Essential Medium (Invitrogen; Thermo Fisher Scientific, Inc.) was incubated with nasal epithelial cell $\left(1 \times 10^{6}\right)$ for at least 24 h. Subsequently, Lipofectamine ${ }^{\circledR} 2000$ transfection reagent (Thermo Fisher Scientific, Inc.) was used according to the manufacturer's protocol to perform siRNA transfection (70 nM/well of siRNA) (49). Following transfection for 36-48 h, cells were lysed, and the proteins were isolated to measure the TLR4 expression via western blotting.

Cell migration assay. For the cell migration assay, Transwell units with an $8 \mu \mathrm{m}$ pore size polycarbonate filter were used. Cells $\left(\sim 1 \times 10^{5}\right)$ were seeded in the upper chamber of the Transwell units with $1 \%$ FBS. The lower chamber was filled with $600 \mu 1$ of L-DMEM supplemented with $1 \%$ FBS. After incubating at $37^{\circ} \mathrm{C}$ for $12 \mathrm{~h}$, the medium was removed, and cells were fixed with $3.7 \%$ paraformaldehyde for $\sim 10 \mathrm{~min}$ (48). The cells in the upper chamber were removed by a cotton swab. Subsequently, the migrated cells were stained with $0.1 \%$ crystal violet for $15 \mathrm{~min}$ at room temperature. Subsequently, the samples were observed under a digital microscope system (IX81; Olympus Corporation). The images were captured, and the migrated cells were recorded in at least five fields (50).

Lactate dehydrogenase ( $L D H)$ assay and caspase-3/-9 activity detection. $\mathrm{LDH}$ is released into the medium when cellular membranes rupture (51). To evaluate the LDH level in the medium, an LDH Release Detection kit (Beyotime Institute of Biotechnology) was used. To analyze changes in caspase-3 and caspase-9, caspase-3/-9 activity kits (Beyotime Institute of Biotechnology) were used according to the manufacturer's protocol (52). To analyze caspase-3 activity, $5 \mu 1$ DEVD-p-NA substrate ( $4 \mathrm{mM}, 200 \mu \mathrm{M}$ final concentration) was added to the samples for $2 \mathrm{~h}$ at $37^{\circ} \mathrm{C}$. To measure caspase- 9 activity, $5 \mu \mathrm{l}$ LEHD-p-NA substrate ( $4 \mathrm{mM}, 200 \mu \mathrm{M}$ final concentration) was added to the nasal epithelial cell $\left(1 \times 10^{6}\right)$ for $1 \mathrm{~h}$ at $37^{\circ} \mathrm{C}$. Subsequently, the wavelength at $400 \mathrm{~nm}$ was recorded via a microplate reader to reflect the caspase- 3 and caspase- 9 activities (53). 
Bromodeoxyuridine (BrdU) assay. To evaluate cellular proliferation, a BrdU assay (Guangzhou RiboBio Co., Ltd., Guangzhou, China) was used according to the method of a previous study (54). Firstly, cells with or without PTEN overexpression were fixed in $4 \%$ paraformaldehyde at $4{ }^{\circ} \mathrm{C}$ for 30 min, followed by permeabilization with $0.5 \%$ Triton X-100 for $\sim 20 \mathrm{~min}$ at room temperature. Subsequently, samples were incubated in $2 \mathrm{~N} \mathrm{HCl}$ solution for 30 min at $37^{\circ} \mathrm{C}$ to unmask the antigens, followed by a neutralization step with $0.1 \mathrm{M}$ sodium tetraborate at room temperature for $30 \mathrm{~min}$. Subsequently, a BrdU antibody (1:200; cat. no. ab8152; Abcam) was incubated with the samples overnight $4^{\circ} \mathrm{C}$. Following three rinses in PBS, a secondary antibody (1:1,000; cat. no. A-21206; Invitrogen; Thermo Fisher Scientific, Inc.) was added to the samples for $1 \mathrm{~h}$ at room temperature (55). Finally, the cells were stained with DAPI (Sigma-Aldrich; Merck KGaA, Darmstadt, Germany) for $5 \mathrm{~min}$ at room temperature to identify the nuclei. Subsequently, the samples were observed under a fluorescence microscope. Images were captured, and the number of BrdU-positive cells was measured via counting at least three random separate fields.

MTT and terminal deoxynucleotidyl-transferase-mediated dUTP nick end labeling (TUNEL) assays. MTT experiments were performed in 96-well plates. Nasal epithelial cell $\left(1 \times 10^{6}\right)$ was washed 3 times with PBS at room temperature, and $50 \mu \mathrm{l}$ MTT reagent was added to each well. The samples were subsequently incubated for $4 \mathrm{~h}$ at $37^{\circ} \mathrm{C}$ in a humid atmosphere containing 5\% $\mathrm{CO}_{2}$. The MTT solution was removed, $200 \mu \mathrm{l}$ dimethyl sulfoxide was added to each sample, and the samples were incubated for $10 \mathrm{~min}$ at room temperature $(13,56)$. Following the addition of Sorensen's buffer, the absorbance at the wavelength of $570 \mathrm{~nm}$ was determined. To detect DNA fragmentation in the cell nuclei (a marker of apoptosis in testicular tissue), a TUNEL assay for nasal epithelial cell $\left(1 \times 10^{6}\right)$ was performed using an In Situ Cell Death Detection kit (Roche Diagnostics GmbH, Mannheim, Germany) according to the manufacturer's protocol (57). DAPI $(5 \mathrm{mg} / \mathrm{ml})$ was used to label the nuclei (at room temperature for $\sim 30 \mathrm{~min}$ ) (58).

Construction of adenovirus for PTEN overexpression. The pDC315-PTEN vector was designed and purchased from Vigene Biosciences, Inc. (Rockville, MD, USA). Briefly, the plasmid $\left(3.0 \mu \mathrm{g}\right.$ per $1 \times 10^{4}$ cells/well $)$ was transfected into $1 \times 10^{6} 293$ cells (CRL-1573 ${ }^{\mathrm{TM}}$; American Type Culture Collection, Manassas, VA, USA) using Lipofectamine $2000^{\circledR}$ (Invitrogen; 110 Thermo Fisher Scientific, Inc.). When the cells detached from the plates, the medium supernatant was collected. Subsequently, the viral supernatant was identified and amplified to obtain adenovirus-PTEN. Subsequently, 100 multiplicity of infection adenovirus-PTEN was transduced into the cells to overexpress PTEN (59). Following the transfection of nasal epithelial cells with Ad-PTEN, the overexpression efficiency of Ad-PTEN-transfected nasal epithelial cell was evaluated via western blotting and an immunofluorescence assay using PTEN antibody. The western blotting and immunofluorescence were performed as aforementioned. PTEN fluorescence was observed under an inverted microscope (excitation wavelength, $550 \mathrm{~nm}$; magnification, x40; BX51; Olympus Corporation).
Statistical analysis. All data are expressed as the mean + standard deviation. Statistical analyses were performed using SPSS software (version 17.0; SPSS, Inc., Chicago, IL, USA). The results from more than two groups were evaluated by one-way analysis of variance followed by the least significant difference test. $\mathrm{P}<0.05$ was considered to indicate a statistically significant difference.

\section{Results}

Regaining PTEN expression increases human nasal epithelial cell survival in the context of $T N F \alpha$-induced inflammatory injury. TNF $\alpha$ was used to induce an inflammatory injury, and nasal epithelial cell viability was detected via MTT assay. As illustrated in Fig. 1A, the TNF $\alpha$ incubation dose-dependently reduced cellular viability. Notably, the minimum cytotoxic concentration of TNFa was $5 \mathrm{ng} / \mathrm{ml}$. These results were similar to a previous study (60). Therefore, based on this data and previous findings (60), a dosage of $5 \mathrm{ng} / \mathrm{ml} \mathrm{TNF} \alpha$ for $\sim 12 \mathrm{~h}$ was used for the subsequent experiments. Additionally, an alteration in PTEN levels was observed following the inflammatory injury. Compared with that of the control cells, PTEN expression was significantly decreased in response to TNF $\alpha$ treatment (Fig. 1B-D). To explain the causal role of PTEN in TNF $\alpha$-induced inflammatory injury, PTEN was overexpressed in TNF $\alpha$-treated nasal epithelial cells. The overexpression efficiency in Ad-PTEN-transfected cells was verified via immunofluorescence assay (Fig. 1E) and western blotting (Fig. 1F). Notably, PTEN overexpression significantly reduced caspase-3 activity compared with that in TNF $\alpha$-treated cells (Fig. 1G), indicating that PTEN overexpression improved nasal epithelial cell survival in the context of TNFa-induced inflammatory injury. The cell morphology with $\mathrm{TNF} \alpha$ treatment is presented in Fig. $1 \mathrm{H}$ and PTEN overexpression preserved cellular organization and normal cell morphology upon TNF $\alpha$ exposure. To provide more direct, evidence for the anti-apoptotic effect of PTEN in inflammatory injury, a TUNEL assay was conducted. Compared with the number of positive cells in the control group, the TNF $\alpha$ treatment increased the number of TUNEL-positive cells (Fig. 1I), and this effect was inhibited by PTEN overexpression. In summary, these data suggested that PTEN overexpression prevented nasal epithelial cell apoptosis during a TNF $\alpha$-induced inflammatory injury.

PTEN reverses the proliferation and migration of nasal epithelial cells during inflammatory injury. In addition to cellular apoptosis, the protective role of PTEN in cellular proliferation and migration, which are vital for airway repair in response to the inflammatory injury, was also observed. Cyclin D1 and Cyclin E expression levels were significantly decreased in response to TNF $\alpha$ treatment, whereas PTEN overexpression reversed this effect (Fig. 2A). Regarding cellular proliferation, Cyclin D1 and Cyclin E interact with each other and generate the cyclin-dependent kinase (Cdk)4/6-cyclin D and/or Cdk2-cyclin E complexes, which accelerate the transition from the G0/G1 to $S$ stage (38). Subsequently, to observe the number of cells at S-phase, BrdU staining was used. Compared with the control group, TNFa incubation significantly reduced the proportion of BrdU-positive cells (Fig. 2B). In comparison, 
A

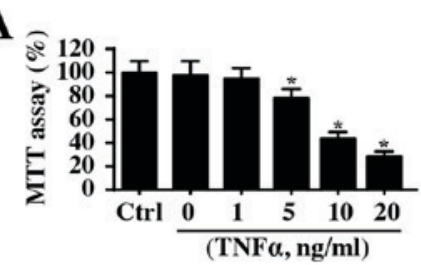

B

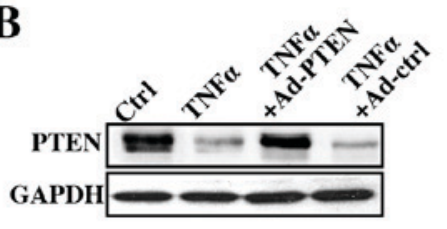

C

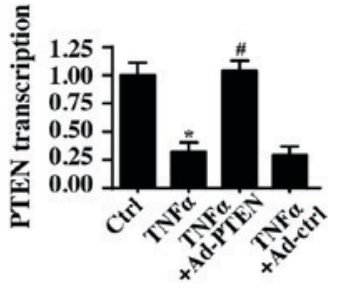

D

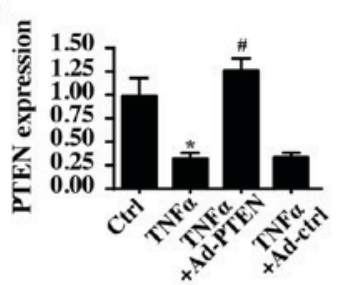

G

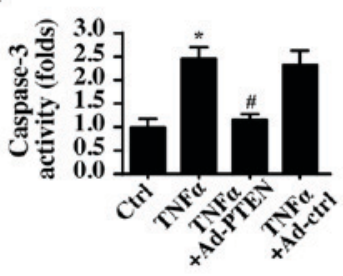

E

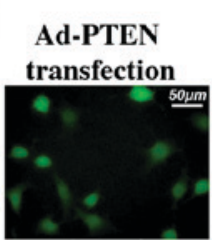

$\mathbf{F}$

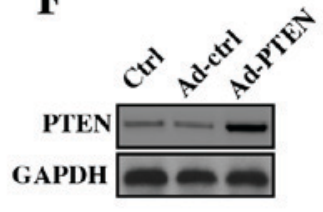

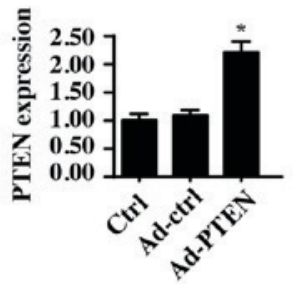

H

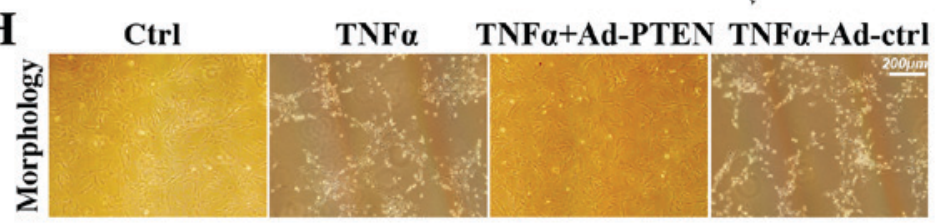

I
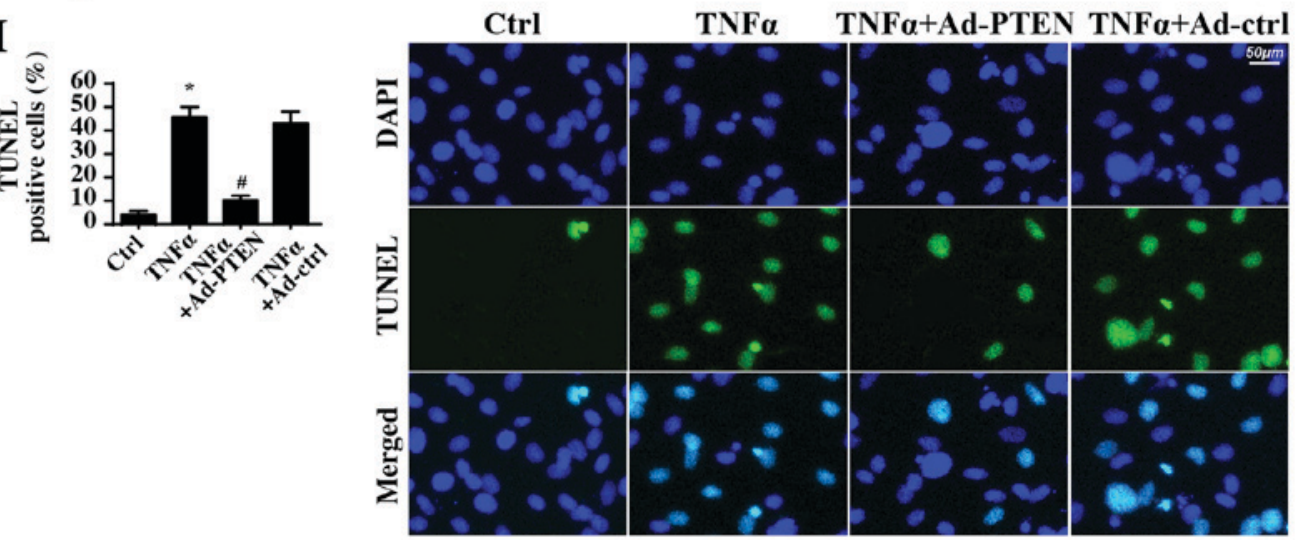

Figure 1. TNF $\alpha$ treatment alleviates PTEN expression in nasal epithelial cells. (A) TNF $\alpha$ treatment reduced nasal epithelial cell viability in a dose-dependent manner, as determined by MTT assay. (B-D) PTEN transcription and expression were downregulated in response to TNFa stimulation. (E) The PTEN overexpression in Ad-PTEN-transfected cell was verified via immunofluorescence assay using PTEN antibody. (F) The overexpression efficiency of Ad-PTEN transfection. Scale bar, $50 \mu \mathrm{m}$. (G) PTEN overexpression alleviated the increased caspase-3 activity induced by TNF $\alpha$ stimulation. (H) The cellular morphology of nasal epithelial cells with PTEN overexpression. Scale bar, $200 \mu \mathrm{m}$. (I) TUNEL assay was carried out to measure the number of the apoptotic nasal epithelial cells. Scale bar, $50 \mu \mathrm{m}$. " $\mathrm{P}<0.05$ vs. Ctrl group or Ad-ctrl group; ${ }^{\#} \mathrm{P}<0.05$ vs. TNF $\alpha$ group. TNF $\alpha$, tumor necrosis factor $\alpha$; PTEN, phosphatase and tensin homolog; Ad, adenovirus; Ctrl, control; TUNEL, terminal deoxynucleotidyl-transferase-mediated dUTP nick end labeling. The experiment was repeated three times.

PTEN overexpression reversed this decrease in the number of BrdU-positive cells.

Subsequently, the cellular migratory response was also observed. In Transwell assays, the number of migrated cells was decreased by $\mathrm{TNF} \alpha$ treatment and was increased to normal levels with PTEN overexpression (Fig. 2C). These data suggested that during TNF $\alpha$-mediated inflammatory injury, PTEN overexpression increased cellular migration. In addition, the chemotactic factor $\mathrm{C}-\mathrm{X}-\mathrm{C}$ chemokine receptor type (CXCR)4/7 expression level was also measured. Notably, the enriched CXCR4/7 expression was inhibited by the TNF $\alpha$ treatment (Fig. 2D). By contrast, PTEN overexpression restored the intracellular CXCR4/7 levels. Collectively, this information indicated that PTEN is necessary for nasal epithelial cell proliferation and migration during inflammatory injury.
Overexpression of PTEN alleviates mitochondrial damage. Recent studies have suggested that mitochondria are a potential target in inflammatory injury $(11,61)$. Mitochondrial damage leads to energy metabolism disorders (62). Moreover, inflammatory injury also activates mitochondrial apoptosis, resulting in cellular death $(63,64)$. Due to energy deficiencies and apoptosis activation, nasal epithelial cells are unable to survive, migrate and proliferate under inflammatory injury conditions (65). Therefore, whether PTEN protected nasal epithelial cells via maintaining mitochondrial homeostasis was investigated. First, cellular ROS levels were detected via flow cytometry. When compared with the control group, TNF $\alpha$ treatment produced excessive cellular ROS levels (Fig. 3A). Bu contrast, PTEN overexpression almost completely reversed the ROS production induced by TNF $\alpha$. As a consequence of 

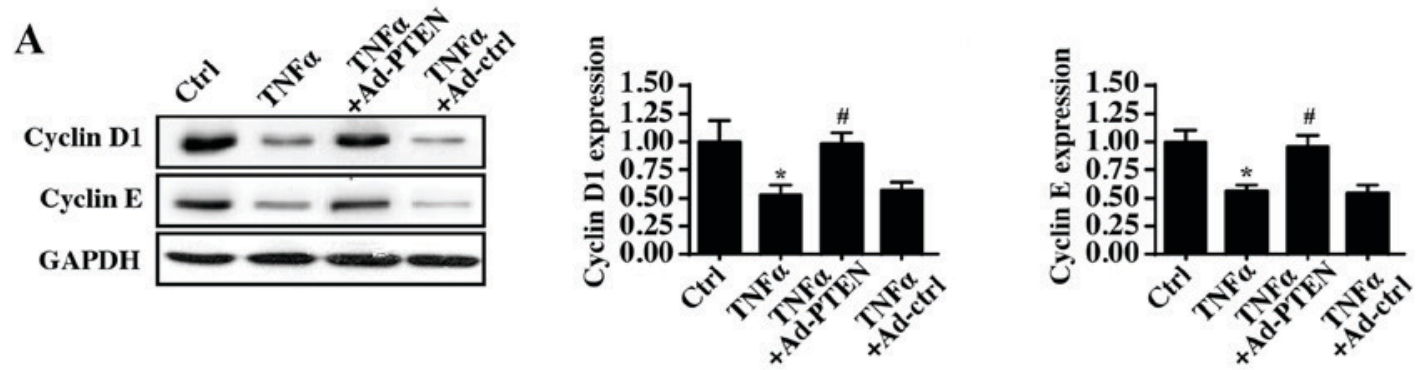

$\mathbf{B}$
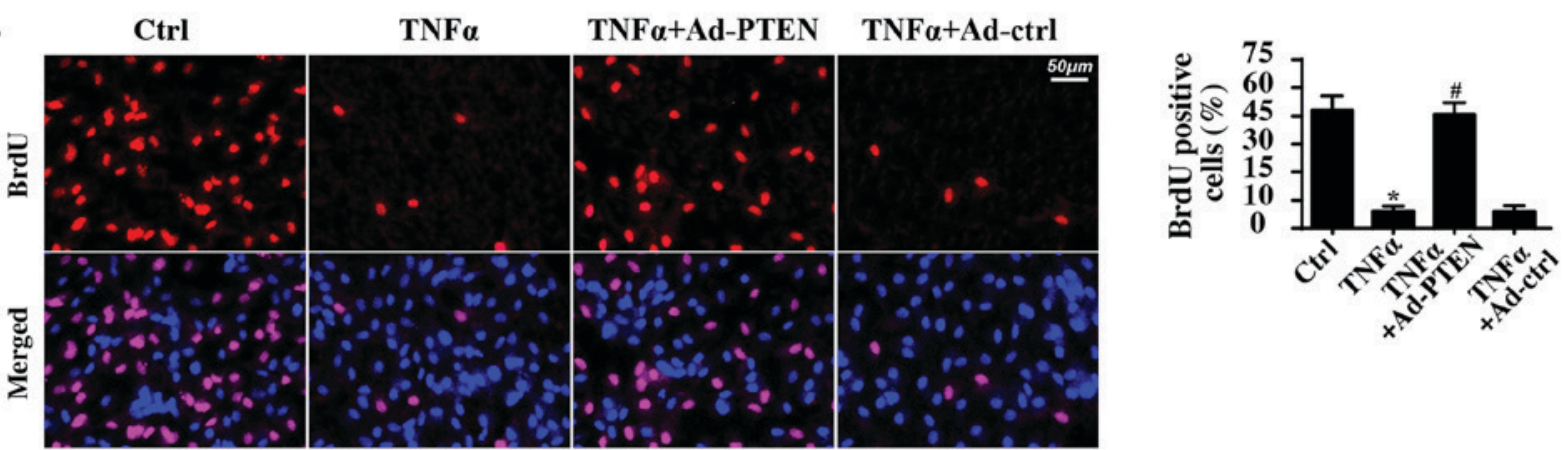

C

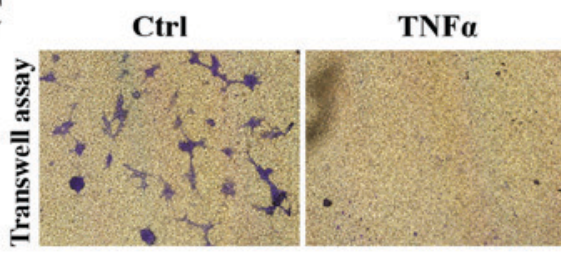

TNF $\alpha+A d-P T E N$
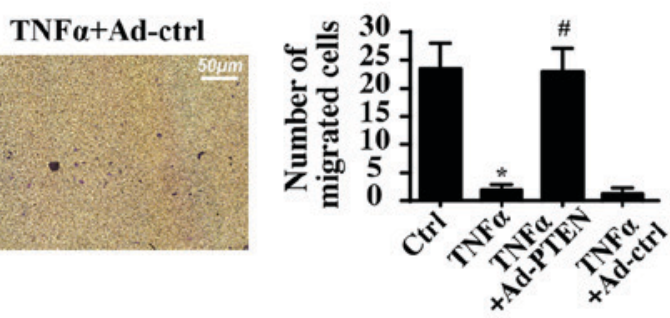

D
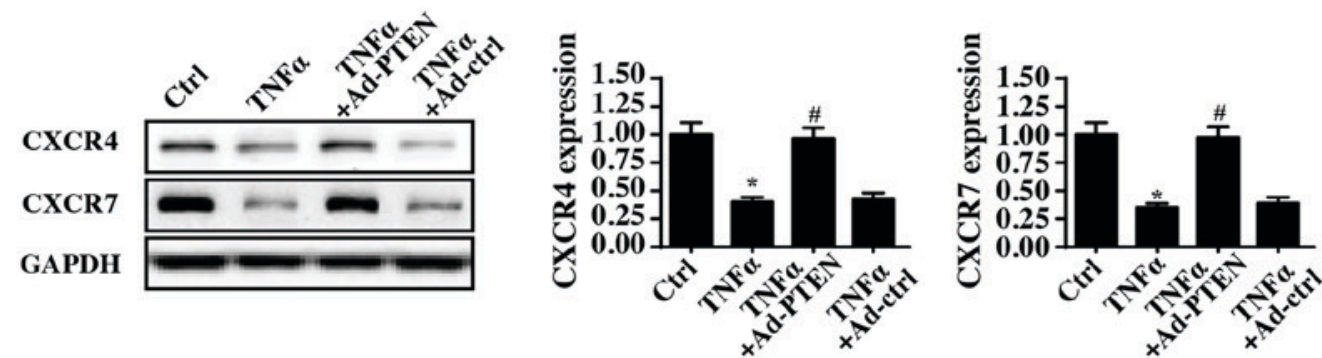

Figure 2. PTEN overexpression sustains nasal epithelial cell proliferation and migration. (A) Cyclin D1 and E expression levels were detected via western blotting. (B) Cell proliferation was observed via BrdU assay. Scale bar, $50 \mu \mathrm{m}$. (C) Transwell assays were used to evaluate cell migration. Scale bar, $50 \mu \mathrm{m}$. (D) CXCR4 and CXCR7 expression levels were determined following TNF $\alpha$ and PTEN overexpression. " P<0.05 vs. Ctrl group; ${ }^{*} \mathrm{P}<0.05$ vs. TNF $\alpha$ group. Ctrl, control; TNF $\alpha$, tumor necrosis factor $\alpha$; Ad, adenovirus; PTEN, phosphatase and tensin homolog; BrdU, bromodeoxyuridine; CXCR, C-X-C chemokine receptor type. The experiment was repeated three times.

the cellular oxidative stress, TNF $\alpha$ treatment mediated the opening of the MPTP, and this effect was inhibited by PTEN overexpression (Fig. 3B). mPTP opening is believed to be the primary initiating factor for the mitochondrial death pathway via facilitating HtrA2/Omi leakage from the mitochondria into the cytoplasm/nucleus (66). Immunofluorescence assays of HtrA2/Omi levels demonstrated low levels of HtrA2/Omi expression in the cytoplasm/nucleus (Fig. 3C). By contrast, TNF $\alpha$ treatment promoted HtrA2/Omi expression in the cytoplasm. Furthermore, western blotting also demonstrated that TNF $\alpha$ treatment increased, whereas PTEN overexpression reduced, the expression of cytoplasmic
HtrA2/Omi (Fig. 3D), indicating that TNF $\alpha$-mediated HrtA2/Om2 leakage into cytoplasm may be repressed by PTEN overexpression. Finally, alterations in the proteins associated to the mitochondrial death pathway were investigated. Bax and Bad expression levels were both upregulated, whereas the expression of protective $\mathrm{Bcl} 2$ was downregulated in response to the $\mathrm{TNF} \alpha$ treatment (Fig. 3D). $\mathrm{Bcl} 2$ interacts with and inhibits Bax in order to limit excessive mPTP opening (67). TNF $\alpha$ treatment also increased caspase-9 and caspase-3 expression (Fig. 3D), indicative of mitochondrial death pathway activation. However, PTEN overexpression corrected the imbalance between $\mathrm{Bcl} 2$ and Bax expression 
A

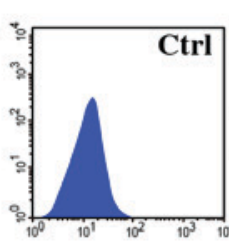

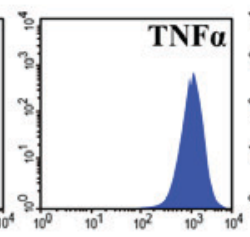
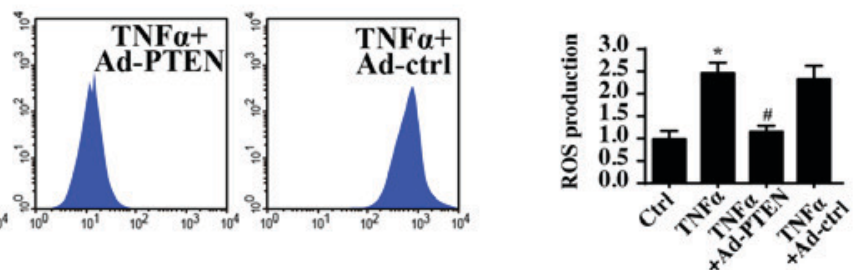

B
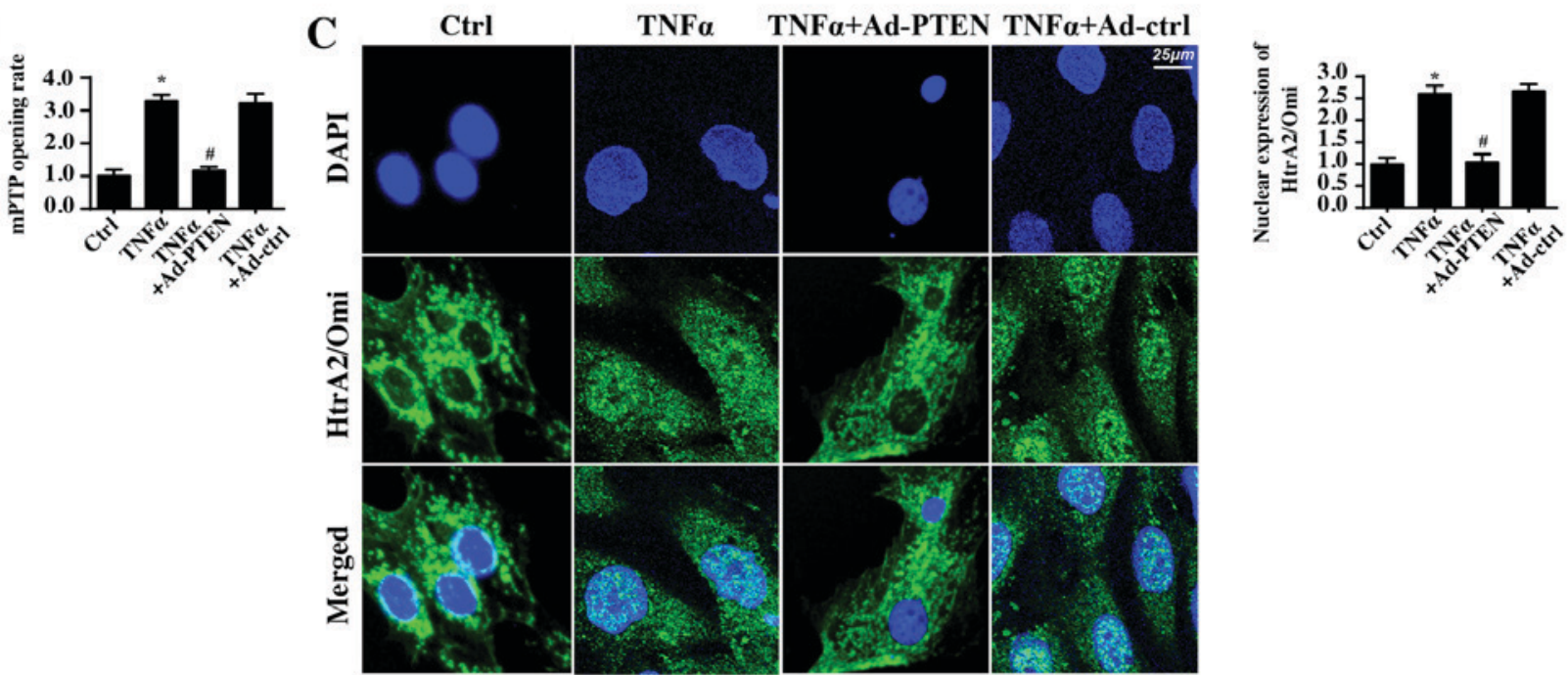

D
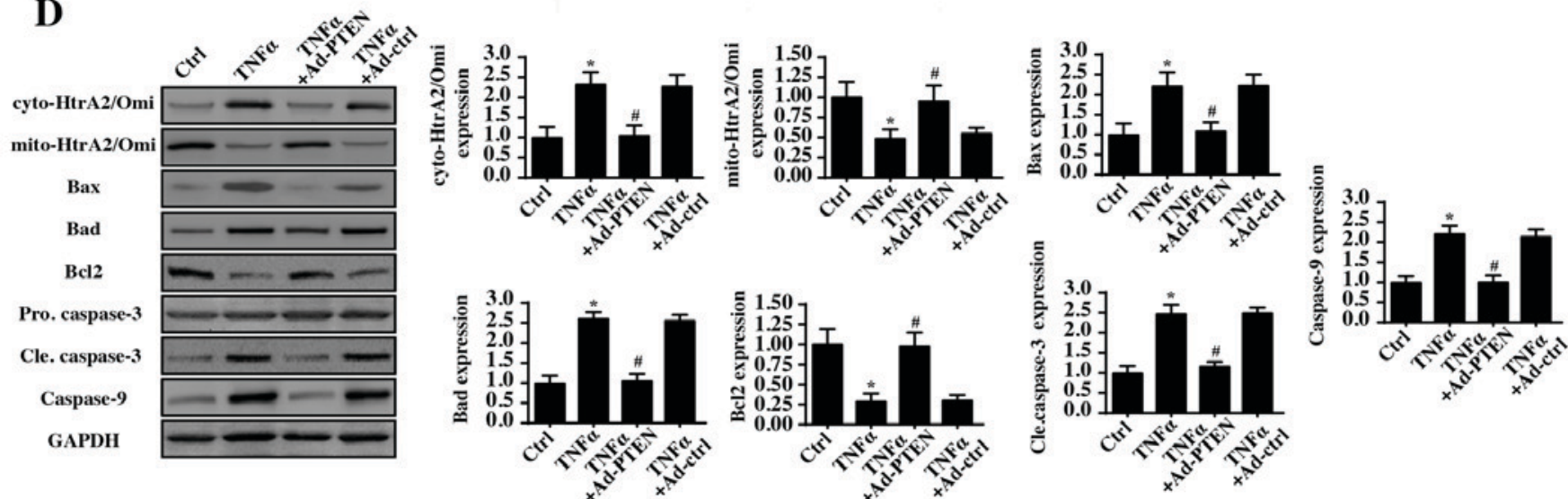

Figure 3. PTEN overexpression protects mitochondria against TNF $\alpha$-mediated inflammatory injury. (A) The alterations in cellular ROS levels were detected via flow cytometry. (B) The mPTP opening rate. (C) Mitochondrial HtrA2/Omi expression was diffused, as detected via immunofluorescence. Scale bar, $25 \mu$ m. (D) Western blotting was used to evaluate the expression of mitochondrial apoptotic proteins following TNF $\alpha$ treatment with or without PTEN overexpression. ${ }^{\text {*P}} \mathrm{P}<0.05$ vs. Ctrl group; ${ }^{\text {P }}<0.05$ vs. TNF $\alpha$ group. Ctrl, control; TNF $\alpha$, tumor necrosis factor $\alpha$; Ad, adenovirus; PTEN, phosphatase and tensin homolog; ROS, reactive oxygen species; mPTP; mitochondria permeability transition pore; HtrA2/Omi, HtrA serine peptidase 2; cyto, cytoplasmic; mito, mitochondrial; Bax, $\mathrm{Bcl}$-associated X protein; Bad, Bcl-2-associated death promoter; Bcl2, B-cell lymphoma. The experiment was repeated three times.

and thus alleviated caspase-3 and caspase-9 expression. These data indicated that PTEN was capable of repressing TNF $\alpha$-induced mitochondrial injury.

PTEN reduces mitophagy activity. Previous studies from several researchers have demonstrated that mitochondrial injury results from the mitophagy, a type of autophagy selective for mitochondria. Moderate mitophagy removes poorly structured mitochondria (59). In contrast, excessive mitophagy induces mitochondrial dysfunction via aberrant mitochondrial degradation (22). To test whether PTEN protected mitochondrial function via inhibiting mitophagy, mitophagy activity was investigated via western blotting.
Compared to the levels in the control group, $\mathrm{TNF} \alpha$ treatment significantly increased the mitochondrial LC3II, Beclin1, p62 and Atg5 levels (Fig. 4A). By contrast, PTEN overexpression significantly alleviated these mitophagy parameters. These data indicated that PTEN inhibited TNF $\alpha$-mediated mitophagy activation.

Furthermore, to provide direct evidence for the inhibitory role of PTEN in mitophagy modulation, immunofluorescence assay of mitophagy via mitochondria and lysosome co-staining was performed. Compared with the control group, TNF $\alpha$ promoted fusion between mitochondria and lysosomes (Fig. 4B), indicative of mitophagy activation. By contrast, PTEN overexpression reduced the overlap 
$\mathbf{A}$
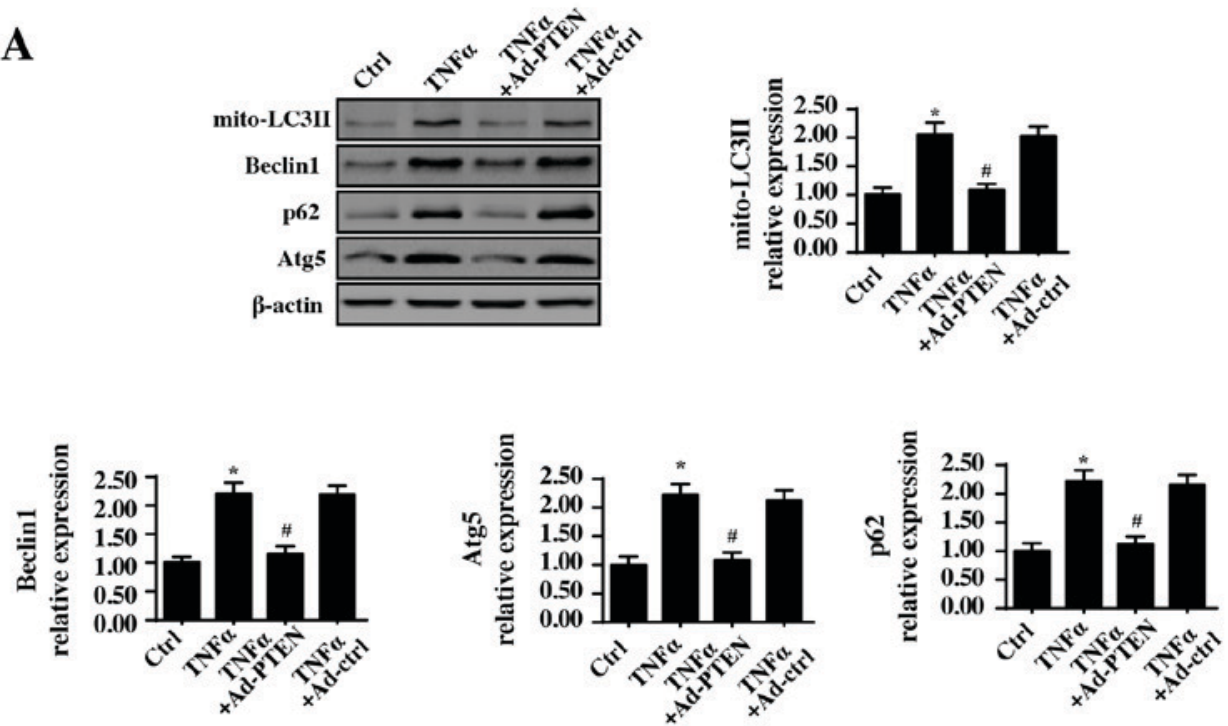

\section{B}
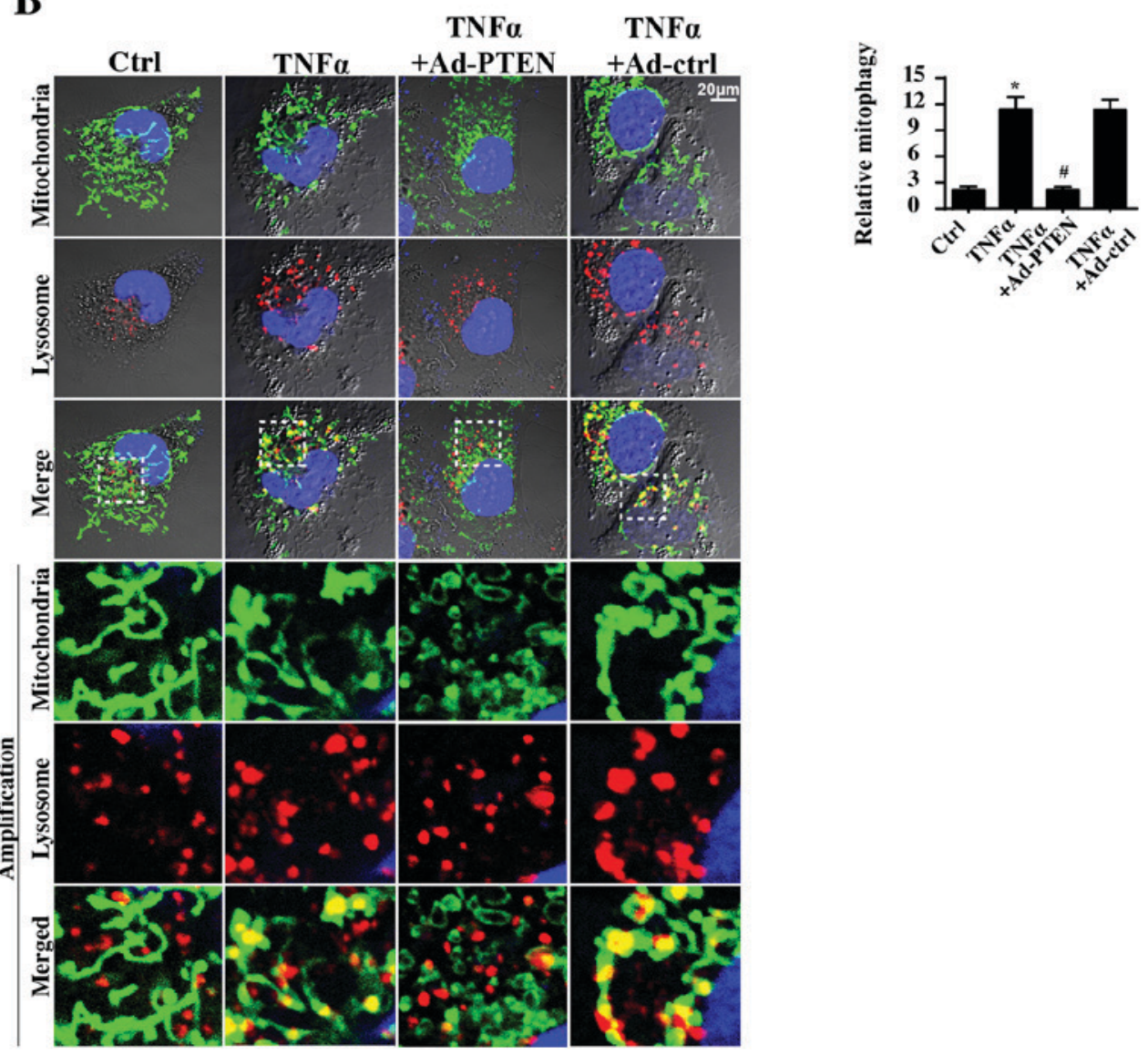

Figure 4. PTEN overexpression inhibits mitophagy activity. (A) Western blotting was used to observe alterations in the mitophagy markers. (B) Immunofluorescence assays of mitophagy was carried out via co-staining of mitochondria and lysosomes and the extent of mitophagy was recorded. Mitophagy is the result of fusion between mitochondria and lysosome. The green mitochondria locates with red lysosome would generate the orange mitophagy. Then, the number of orange dots were measured to quantify the number of mitophagy. Scale bar, $20 \mu \mathrm{m}$. ${ }^{*}<0.05$ vs. Ctrl group; ${ }^{2} \mathrm{P}<0.05$ vs. TNF $\alpha$ group. Ctrl, control; TNF $\alpha$, tumor necrosis factor $\alpha$; Ad, adenovirus; PTEN, phosphatase and tensin homolog; mito, mitochondrial; LC3II, microtubule-associated protein light chain 3 II; p62, Sequestome-1; Atg5, autophagy protein 5. The experiment was repeated three times.

between mitochondrial and lysosomal staining, suggestive of mitophagy inhibition.

Mitophagy inhibition induced by PTEN overexpression provides mitochondrial protection. To determine whether mitophagy inhibition by PTEN overexpression was responsible for the mitochondrial protection, mitophagy activity in PTEN-overexpressing cells was reactivated via FCCP, a mitophagy activator. Meanwhile, mitophagy activity was also inhibited via 3-MA in TNF $\alpha$-treated cells, which was used as the negative control group. Subsequently, mitochondrial damage was detected via staining with JC-1, a 
A
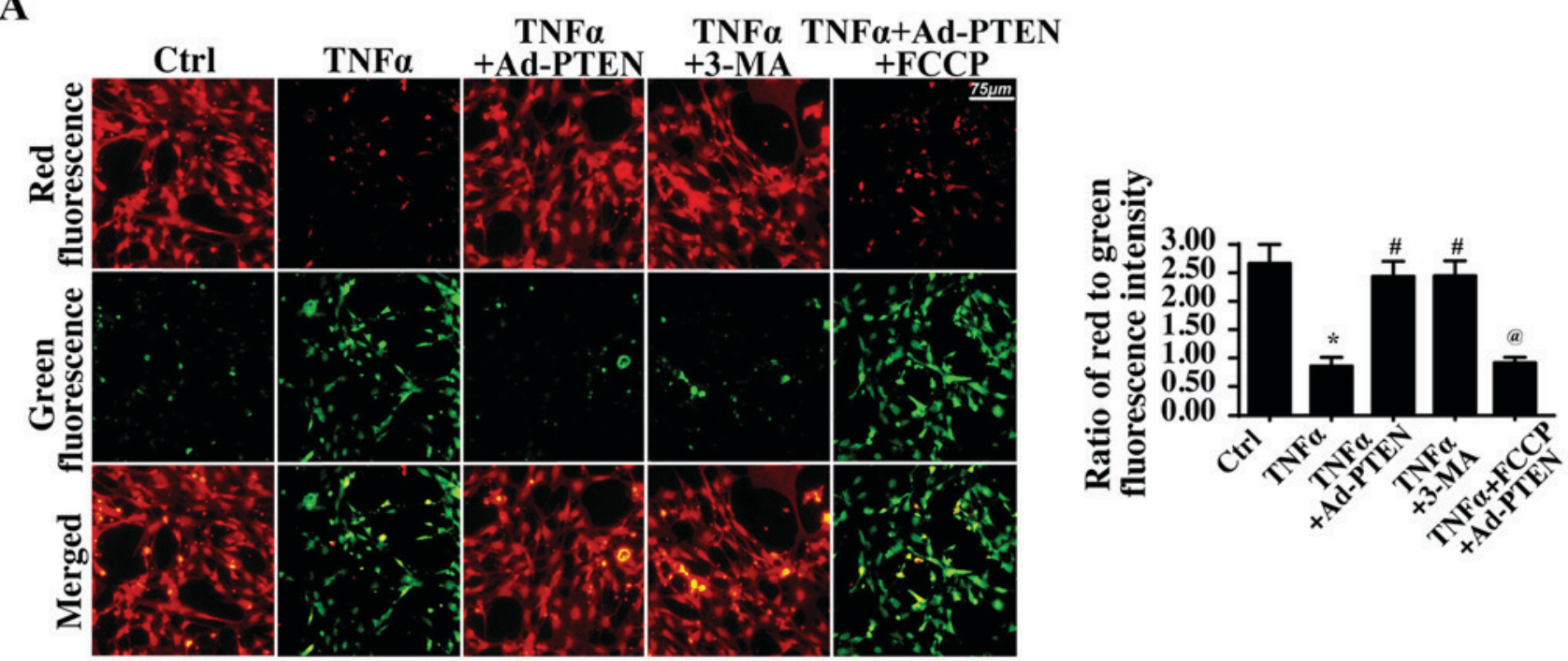

B
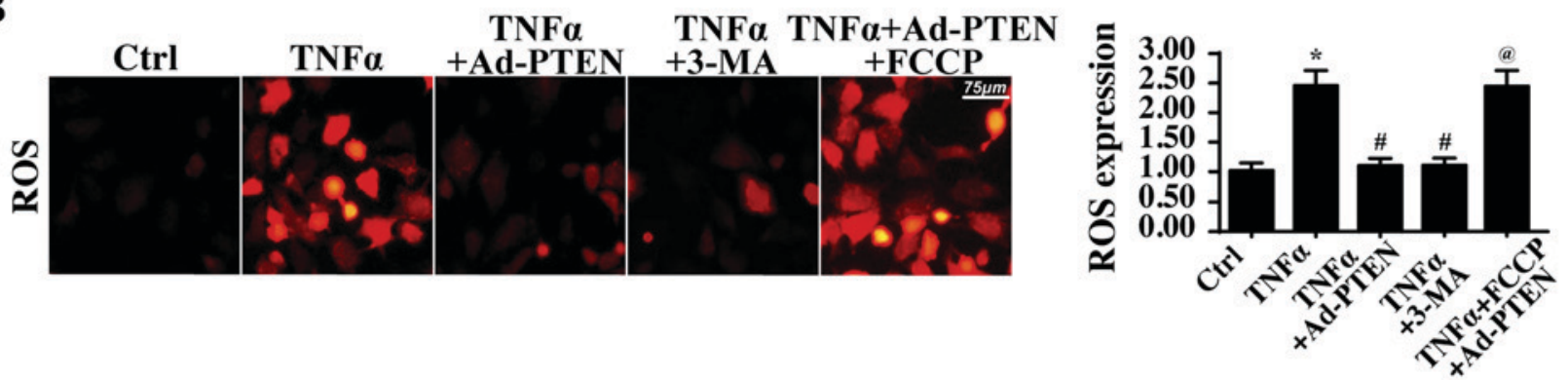

C

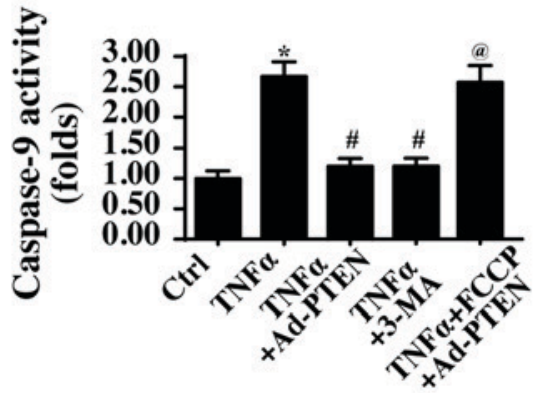

D

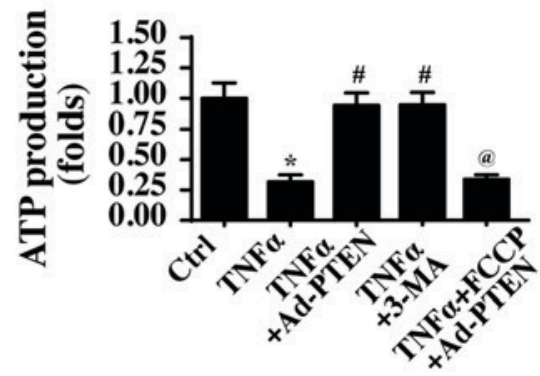

Figure 5. PTEN-regulated mitophagy influences mitochondrial function. (A) Mitochondrial potential was observed via JC1 staining. Red fluorescence indicated a normal mitochondrial potential, whereas green fluorescence suggested a damaged mitochondrial potential. Scale bar, $75 \mu \mathrm{m}$. (B) The cellular ROS level was measured using a dihydroethidium probe. Scale bar, $75 \mu \mathrm{m}$. (C) Caspase-9 activity was detected to reflect mitochondrial apoptosis during mitophagy activation and/or inactivation. (D) ATP production was evaluated via ELISA. ${ }^{*} \mathrm{P}<0.05$ vs. Ctrl group; ${ }^{\prime} \mathrm{P}<0.05$ vs. TNF $\alpha$ group; ${ }^{\circledR} \mathrm{P}<0.05$ vs. TNF $\alpha+\mathrm{Ad}-\mathrm{PTEN}$ group. Ctrl, control; TNF $\alpha$, tumor necrosis factor $\alpha$; Ad, adenovirus; PTEN, phosphatase and tensin homolog; 3-MA, 3-methyladenine; FCCP, carbonyl cyanide-p-trifluoromethoxyphenylhydrazone; ROS, ROS, reactive oxygen species; ATP, adenosine triphosphate. The experiment was repeated three times.

mitochondrial potential-sensitive dye. Compared with that of the control cells, TNF $\alpha$ treatment reduced the mitochondrial potential (Fig. 5A), and this effect was inhibited by 3-MA or PTEN overexpression, suggesting that mitophagy inhibition reversed mitochondrial function. By contrast, mitophagy activation in PTEN-overexpressing cells disrupted the mitochondrial potential. In addition, the cellular oxidative stress level was also investigated via ROS staining. Compared with that of the control group, the cellular ROS level was increased in the TNF $\alpha$-treated cells but was decreased to normal levels with 3-MA treatment or with PTEN overexpression (Fig. 5B). Notably, mitophagy activation reversed the inhibitory effects of
PTEN-overexpression on ROS overproduction. Furthermore, it was also detected caspase-9 activity, which is activated in response to mitochondrial damage. Notably, caspase-9 activity was upregulated following TNF $\alpha$ treatment. In contrast, 3-MA treatment or PTEN overexpression significantly reduced caspase-9 activity. However, mitophagy reactivation by FCCP in PTEN-overexpressing cells again increased caspase-9 activity (Fig. 5C). Finally, the changes in cellular ATP production were also investigated. Compared with the ATP generated in the control group, TNF $\alpha$ treatment reduced ATP production, and this effect was reversed by 3-MA treatment or PTEN overexpression. Notably, mitophagy activation rescued 
A

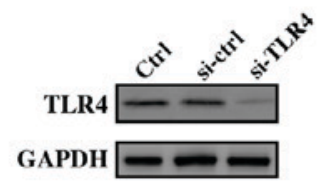

B
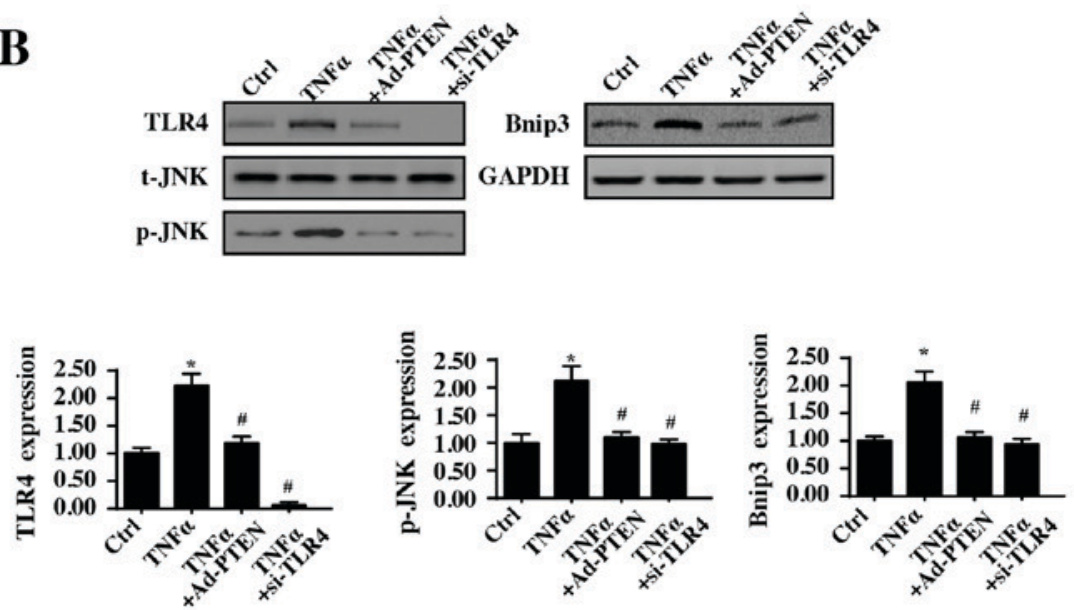

C
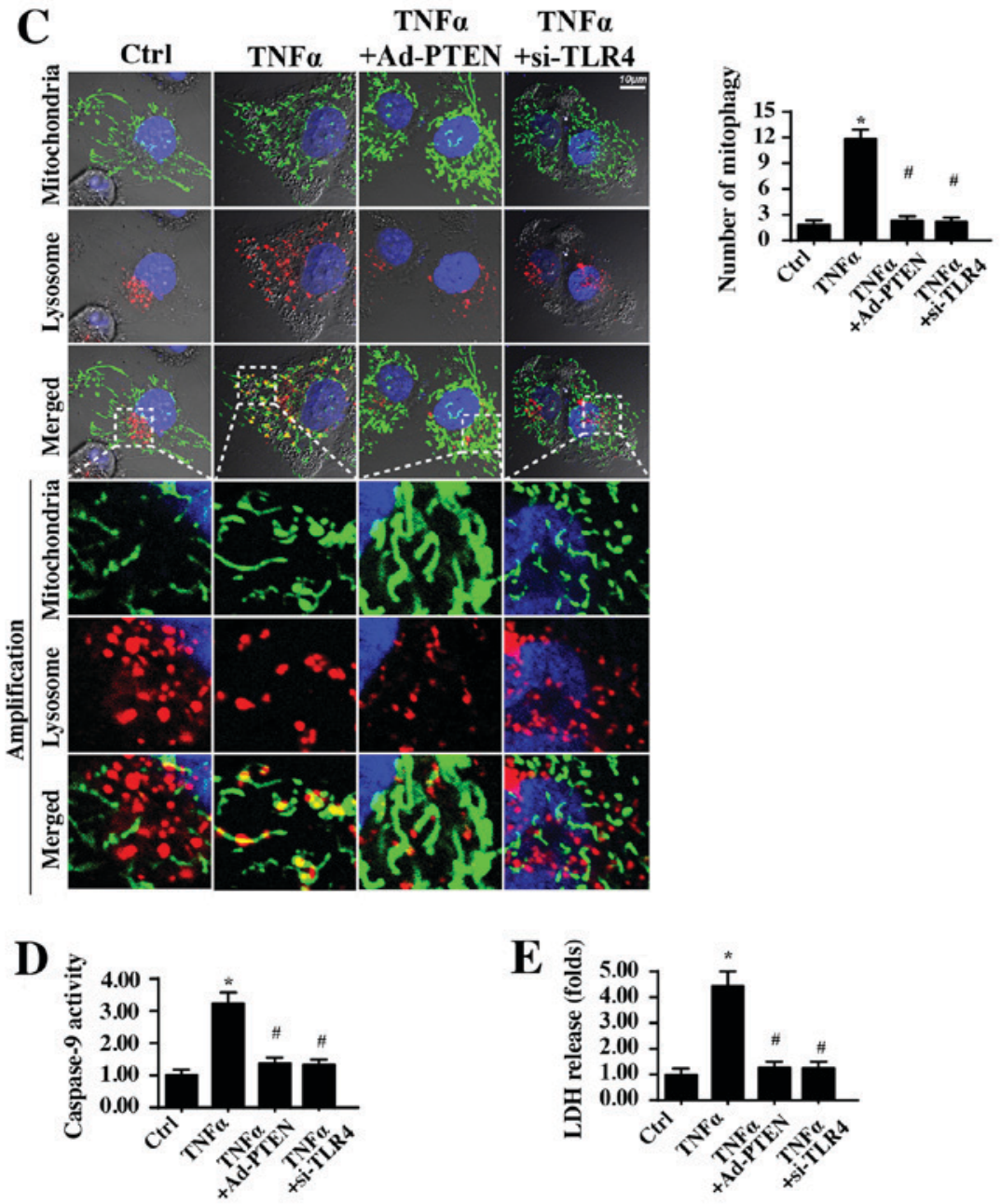

Figure 6. PTEN controls mitophagy activity via the TLR4-JNK-Bnip3 pathway. (A) TLR4 siRNA was used to reduce TLR4 expression. (B) Western blotting was used to analyze the expression of TLR4, phosphorylated JNK and Bnip3 with or without PTEN overexpression and TLR4 silencing. (C) Immunofluorescence assays of mitophagy were carried out via co-staining mitochondria (TOM20 homolog) and lysosomes (lysosome-associated membrane glycoprotein 1). The boxed area under each image represents the amplification of the white square and the amount of mitophagy was recorded. Scale bar, $10 \mu \mathrm{m}$. (D) Caspase-9 activity was detected to reflect mitochondrial apoptosis when TLR4 expression was knocked down. (E) LDH release assays were carried to measure cell death when TLR4 expression was silenced. ${ }^{*} \mathrm{P}<0.05$ vs. Ctrl group or si-ctrl group; ${ }^{*} \mathrm{P}<0.05$ vs. TNF $\alpha$ group. Ctrl, control; si, small interfering RNA; TLR4, Toll-like receptor 4; TNF $\alpha$, tumor necrosis factor $\alpha$; Ad, adenovirus; PTEN, phosphatase and tensin homolog; t, total; JNK, c-Jun kinase; p, phosphorylated; Bnip3, Bcl2-interacting protein 3; $\mathrm{LDH}$, lactate dehydrogenase. The experiment was repeated three times. 


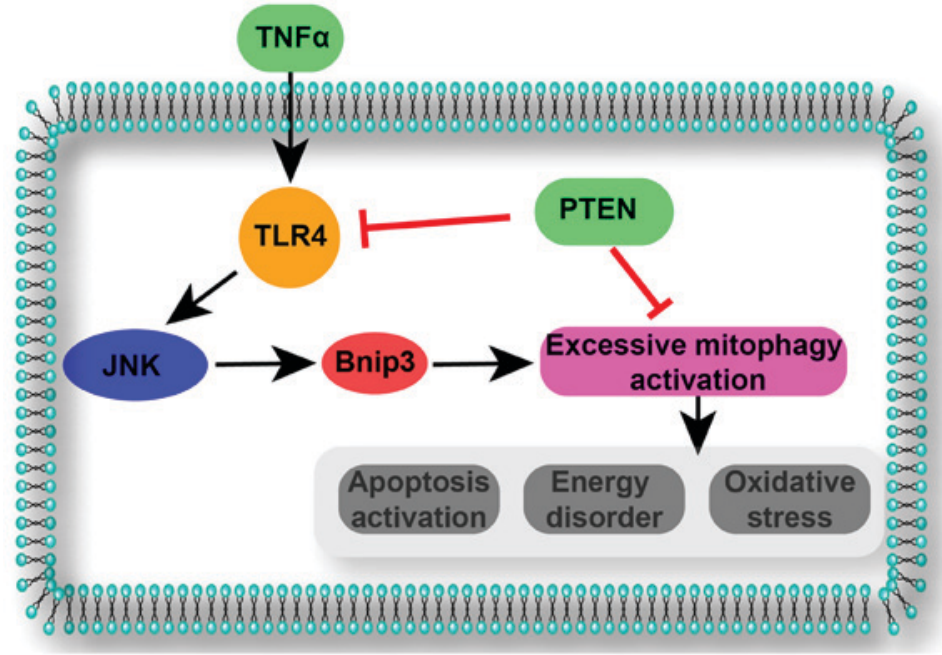

Figure 7. Schematic demonstrating that TNF $\alpha$ may induce mitochondrial dysfunction, energy metabolism disorder and cellular death via mitophagy. Expression of PTEN may inhibit TLR4-JNK-Bnip3 pathways thereby blocking mitophagy activity and increasing the sensitivity of nasal epithelial cell to TNFa-induced cell death. TNF $\alpha$, tumor necrosis factor $\alpha$; TLR4, Toll-like receptor 4; PTEN, phosphatase and tensin homolog; JNK, c-Jun kinase; Bnip3, Bcl2-interacting protein 3.

this decline in cellular ATP production (Fig. 5D). In summary, these data indicated that PTEN overexpression protected mitochondrial homeostasis via suppressing mitophagy activity.

PTENregulatesmitophagyviarepressing the TLR4-JNK-Bnip3 pathway. To determine the mechanism by which PTEN inhibits mitophagy, the JNK-Bnip3 pathway was investigated. Previous reports have demonstrated that mitophagy is activated via the JNK-Bnip3 axis in fatty liver disease (59), colorectal cancer (68), hepatocellular carcinoma (24) and cardiac reperfusion injury (23). Accordingly, whether PTEN modified mitophagy via the JNK-Bnip3 pathway was investigated. Additionally, to determine whether TLR4 was involved in the JNK-Bnip3 pathway activation, TLR4 expression we knocked down using siRNA (Fig. 6A). In the present study, it was demonstrated that JNK and Bnip3 were both activated in response to the TNF $\alpha$ treatment, via western blotting (Fig. 6B). By contrast, PTEN overexpression significantly reduced JNK phosphorylation levels and Bnip3 expression in TNF $\alpha$-treated cells.

To investigate the upstream signaling responsible for the JNK-Bnip3 pathway activation by TNFa, TLR4 expression was measured. Notably, TLR4 expression was increased in response to the TNF $\alpha$ treatment, and this trend was strongly inhibited by PTEN overexpression (Fig. 6B). Notably, following knockdown of TLR4 expression in $\mathrm{TNF} \alpha$-treated cells, JNK phosphorylation levels and Bnip3 expression were decreased (Fig. 6B). These data indicated that TLR4 functioned upstream of JNK-Bnip3 axis activation. Additionally, whether TLR4 was also associated with mitophagy activation, an immunofluorescence assay of mitophagy was conducted. As demonstrated in Fig. 6C, $\mathrm{TNF} \alpha$-mediated mitochondria-lysosome fusion was inhibited by TLR4 silencing or PTEN overexpression, suggesting that TLR4 was necessary for TNF $\alpha$-induced mitophagy activation. Furthermore, whether TLR4 was also required for $\mathrm{TNF} \alpha$-associated mitochondrial damage and cellular death, caspase- 9 activity was evaluated, and the LDH release assay was conducted. TLR4 knockdown significantly reduced caspase-9 activity (Fig. 6D) and LDH release (Fig. 6E); similar results were also obtained in PTEN-overexpressing cells. In summary, the present data indicated that TNF $\alpha$ activated mitophagy via the TLR4-JNK-Bnip3 pathway, leading to mitochondrial damage and cellular death. However, PTEN overexpression inhibited the TLR4-JNK-Bnip3-mitophagy axis, maintaining mitochondrial homeostasis and providing a survival advantage for nasal epithelial cells under TNF $\alpha$-induced inflammatory injury (Fig. 7).

\section{Discussion}

In the present study, the following were demonstrated: i) PTEN was downregulated innasalepithelialcells underTNF $\alpha$-induced inflammatory injury; ii) regaining PTEN expression alleviated inflammation-mediated cellular apoptosis, proliferation arrest and migration inhibition; iii) mechanistically, PTEN overexpression attenuated mitochondrial dysfunction via repression of mitophagy activity; iv) inflammation-activated mitophagy resulted in aberrant mitochondrial degradation, leading to a reduced energy supply and apoptosis activation; and v) PTEN overexpression abrogated lethal mitophagy via blocking the TLR4-JNK-Bnip3 pathway, maintaining mitochondrial homeostasis and promoting cellular survival in the context of inflammatory injury. Based on the above findings, the mechanism underlying inflammatory injury-induced apoptosis in nasal epithelial cells was investigated; this pathogenesis was associated with PTEN downregulation, mitophagy upregulation and TLR4-JNK-Bnip3 pathway activation. To the best of our knowledge, this is the first study to describe the role of PTEN-associated mitophagy in nasal epithelial cell inflammatory injury.

Several studies have reported that COPD development is associated with chronic nasal and sinus inflammation (69). In addition, anti-inflammation therapy is effective for alleviating upper airway symptoms such as rhinorrhea, nasal obstruction and sneezing (70). Therefore, this information confirmed that chronic nasal and sinus inflammatory injury is the primary pathogenesis for COPD progression. Accordingly, 
identifying the molecular basis underlying nasal and sinus inflammatory injuries may uncover potential therapeutic targets for clinical practice. In response to TNFa stimulation, PTEN expression was downregulated in nasal epithelial cells. However, reintroduction of PTEN expression rescued nasal epithelial cell viability, growth and mobility. Accordingly, these data identified PTEN as an endogenous defender against inflammation-mediated cellular damage in nasal epithelial cells. Previous studies have also illustrated the beneficial role of PTEN in acute kidney injury (28), diabetes (71), cardiomyopathy (72) and chronic fatty liver disease (73). Therefore, an approach to reverse PTEN activity could be considered as adjuvant therapy to enhance anti-inflammatory treatments in patients with chronic nasal and sinus inflammation, but this needs to be investigated further.

Functional studies have demonstrated that inflammation induced nasal epithelial cell death via mitophagy (74). In response to $\mathrm{TNF} \alpha$ stimulation in the current study, the TLR4-JNK-Bnip3 pathway was upregulated and was accompanied by increased mitophagy activity. Excessive mitophagy results in aberrant mitochondrial degradation, leading to a shortage in the energy supply and mitochondrial apoptosis activation $(59,63)$. Notably, several studies have reported the protective role of mitophagy in acute cardiac ischemia reperfusion injury (19), diabetes (75) and non-alcoholic fatty liver disease (59). These studies noted that moderate mitophagy activation removed the damaged mitochondria in a timely manner and maintained mitochondrial homeostasis. Notably, a report has argued that mitophagy is harmful to cell viability (62). Excessive mitophagy activation impaired liver cancer migration and promoted endothelial mitochondrial apoptosis $(22,24)$. This discrepancy may result from the different mitophagy regulatory signaling pathways. Several studies have confirmed that various mitophagy activation pathways distinctly influence mitophagy function and cell fate $(59,76)$. Notably, Bnip3-associated mitophagy is lethal for cardiomyocytes (23,77), liver cancer (24) and colorectal cancer (68), which is similar to the present findings. These findings hinted that modulating Bnip3-mediated mitophagy is vital for nasal epithelial cell survival under inflammatory injury.

Furthermore, the TLR4-JNK-Bnip3 pathway seemed to be responsible for mitophagy activation under inflammatory injury, in vitro. However, PTEN overexpression had the ability to block the TLR4-JNK-Bnip3 pathway. Notably, a previous study reported the inhibitory effects of PTEN overexpression on TLR4 or JNK expression (24). Accordingly, to the best of our knowledge, this is the first study to establish the regulatory role of PTEN in the TLR4-JNK-Bnip3 pathway in chronic nasal and sinus inflammation. Therefore, the present data provided more information about the association between PTEN and the TLR4-JNK-Bnip3 pathway.

Collectively, the present data investigated the molecular mechanism underlying inflammation-associated nasal epithelial cell damage. Inflammation-induced PTEN downregulation resulted in TLR4-JNK-Bnip3-mitophagy pathway activation, which eventually amplified the cellular death signals in nasal epithelial cells. However, rescuing PTEN activity blocked the TLR4-JNK-Bnip3 pathway and halted mitophagy, favoring nasal epithelial cell survival in inflammatory injury.

\section{Acknowledgements}

Not applicable.

\section{Funding}

No funding was received.

\section{Availability of data and materials}

The datasets used and/or analyzed during the current study are available from the corresponding author on reasonable request.

\section{Authors' contributions}

ML, SW and XY made substantial contributions to the concept and design of the present study, performance of experiments, data analysis and interpretation, and manuscript writing.

\section{Ethics approval and consent to participate}

Not applicable.

\section{Patient consent for publication}

Not applicable.

\section{Competing interests}

The authors declare that they have no competing interests.

\section{References}

1. Lv H, Liu Q, Wen Z, Feng H, Deng X and Ci X: Xanthohumol ameliorates lipopolysaccharide (LPS)-induced acute lung injury via induction of AMPK/GSK3 $\beta$-Nrf2 signal axis. Redox Biol 12: 311-324, 2017.

2. Cheng KJ, Bao YY and Zhou SH: The role of hypoxia inducible factor in nasal inflammations. Eur Rev Med Pharmacol Sci 20: 5067-5076, 2016.

3. Bergmark RW and Pynnonen M: Diagnosis and first-line treatment of chronic sinusitis. JAMA 318: 2344-2345, 2017.

4. Smith KA, Waypa GB and Schumacker PT: Redox signaling during hypoxia in mammalian cells. Redox Biol 13: 228-234, 2017.

5. Blackburn NJR, Vulesevic B, McNeill B, Cimenci CE, Ahmadi A, Gonzalez-Gomez M, Ostojic A, Zhong Z, Brownlee M, Beisswenger PJ, et al: Methylglyoxal-derived advanced glycation end products contribute to negative cardiac remodeling and dysfunction post-myocardial infarction. Basic Res Cardiol 112: 57, 2017.

6. Griffiths HR, Gao D and Pararasa C: Redox regulation in metabolic programming and inflammation. Redox Biol 12: 50-57, 2017.

7. Brasacchio D, Alsop AE, Noori T, Lufti M, Iyer S, Simpson KJ Bird PI, Kluck RM, Johnstone RW and Trapani JA: Epigenetic control of mitochondrial cell death through PACS1-mediated regulation of BAX/BAK oligomerization. Cell Death Differ 24: 961-970, 2017.

8. Xu P, Wang J, Hong F, Wang S, Jin X, Xue T, Jia L and Zhai Y: Melatonin prevents obesity through modulation of gut microbiota in mice. J Pineal Res 62, 2017.

9. Yin Y, Li F, Li S, Cai J, Shi J and Jiang Y: TLR4 influences hepatitis $\mathrm{B}$ virus related hepatocellular carcinoma by regulating the Wnt// $\beta$-catenin pathway. Cell Physiol Biochem 42: 469-479, 2017.

10. Du GQ, Shao ZB, Wu J, Yin WJ, Li SH, Wu J, Weisel RD, Tian JW and Li RK: Targeted myocardial delivery of GDF11 gene rejuvenates the aged mouse heart and enhances myocardial regeneration after ischemia-reperfusion injury. Basic Res Cardiol 112: 7, 2017 
11. Galley HF, McCormick B, Wilson KL, Lowes DA, Colvin L and Torsney C: Melatonin limits paclitaxel-induced mitochondrial dysfunction in vitro and protects against paclitaxel-induced neuropathic pain in the rat. J Pineal Res 63, 2017.

12. Kozlov AV, Lancaster JR Jr, Meszaros AT and Weidinger A: Mitochondria-meditated pathways of organ failure upon inflammation. Redox Biol 13: 170-181, 2017.

13. Han L, Wang H,Li L, Li X, Ge J, Reiter RJ and Wang Q: Melatonin protects against maternal obesity-associated oxidative stress and meiotic defects in oocytes via the SIRT3-SOD2-dependent pathway. J Pineal Res 63, 2017.

14. Zhou H, Yang J, Xin T, Li D, Guo J, Hu S, Zhou S, Zhang T, Zhang Y,Han T and Chen Y: Exendin-4 protects adipose-derived mesenchymal stem cells from apoptosis induced by hydrogen peroxide through the PI3K/Akt-Sfrp2 pathways. Free Radic Biol Med 77: 363-375, 2014

15. Zhang Y, Zhou H, Wu W, Shi C, Hu S, Yin T, Ma Q, Han T, Zhang Y, Tian F and Chen Y: Liraglutide protects cardiac microvascular endothelial cells against hypoxia/reoxygenation injury through the suppression of the SR-Ca(2+)-XO-ROS axis via activation of the GLP-1R/PI3K/Akt/survivin pathways. Free Radic Biol Med 95: 278-292, 2016.

16. Zhou H, Zhu P, Guo J, Hu N, Wang S, Li D, Hu S, Ren J, Cao F and Chen Y: Ripk3 induces mitochondrial apoptosis via inhibition of FUNDC1 mitophagy in cardiac IR injury. Redox Biol 13: 498-507, 2017.

17. Schock SN, Chandra NV, Sun Y, Irie T, Kitagawa Y, Gotoh B, Coscoy L and Winoto A: Induction of necroptotic cell death by viral activation of the RIG-I or STING pathway. Cell Death Differ 24: 615-625, 2017.

18. Liu L, Feng D, Chen G, Chen M, Zheng Q, Song P, Ma Q, Zhu C, Wang R, Qi W, et al: Mitochondrial outer-membrane protein FUNDC1 mediates hypoxia-induced mitophagy in mammalian cells. Nat Cell Biol 14: 177-185, 2012.

19. Zhou H, Li D, Zhu P, Hu S, Hu N, Ma S, Zhang Y, Han T, Ren J, Cao F and Chen Y: Melatonin suppresses platelet activation and function against cardiac ischemia/reperfusion injury via PPARgamma/FUNDC1/mitophagy pathways. J Pineal Res 63, 2017.

20. Chen L, Liu L, Li Y and Gao J: Melatonin increases human cervical cancer HeLa cells apoptosis induced by cisplatin via inhibition of JNK/Parkin/mitophagy axis. In Vitro Cell Dev Biol Anim 54: 1-10, 2018.

21. Nunez-Gomez E, Pericacho M, Ollauri-Ibáñez C, Bernabéu C and López-Novoa JM: The role of endoglin in post-ischemic revascularization. Angiogenesis 20: 1-24, 2017.

22. Zhou H, Zhang Y, Hu S, Shi C, Zhu P, Ma Q, Jin Q, Cao F, Tian F and Chen Y: Melatonin protects cardiac microvasculature against ischemia/reperfusion injury via suppression of mitochondrial fissio n-VDAC1-HK2-mPTP-mitophagy axis. J Pineal Res 63, 2017.

23. Jin Q, Li R, Hu N, Xin T, Zhu P, Hu S, Ma S, Zhu H, Ren J and Zhou H: DUSP1 alleviates cardiac ischemia/reperfusion injury by suppressing the Mff-required mitochondrial fission and Bnip3-related mitophagy via the JNK pathways. Redox Biol 14: 576-587, 2018.

24. Shi C, Cai Y, Li Y, Li Y, Hu N, Ma S, Hu S, Zhu P, Wang W and Zhou H: Yap promotes hepatocellular carcinoma metastasis and mobilization via governing cofilin/F-actin/lamellipodium axis by regulation of JNK/Bnip3/SERCA/CaMKII pathways. Redox Biol 14: 59-71, 2018.

25. Jia M, Chen X, Liu J and Chen J: PTEN promotes apoptosis of $\mathrm{H} 2 \mathrm{O} 2$-injured rat nasal epithelial cells through PI3K/Akt and other pathways. Mol Med Rep 17: 571-579, 2018.

26. Ackermann M, Kim YO, Wagner WL, Schuppan D, Valenzuela CD, Mentzer SJ, Kreuz S, Stiller D, Wollin L and Konerding MA: Effects of nintedanib on the microvascular architecture in a lung fibrosis model. Angiogenesis 20: 359-372, 2017.

27. Gadicherla AK, Wang N, Bulic M, Agullo-Pascual E, Lissoni A De Smet M, Delmar M, Bultynck G, Krysko DV, Camara A, et al Mitochondrial Cx43 hemichannels contribute to mitochondrial calcium entry and cell death in the heart. Basic Res Cardiol 112: 27, 2017

28. Yang N, Zhang H, Cai X and Shang Y: Epigallocatechin-3-gallate inhibits inflammation and epithelialmesenchymal transition through the PI3K/AKT pathway via upregulation of PTEN in asthma. Int J Mol Med 41: 818-828, 2018.

29. Zhou J, Zhong J, Lin S, Huang Z, Chen H, Tang S, Yang C and Fan Y: Inhibition of PTEN activity aggravates post renal fibrosis in mice with ischemia reperfusion-induced acute kidney injury. Cell Physiol Biochem 43: 1841-1854, 2017.
30. Xiao L, Xu X, Zhang F, Wang M, Xu Y, Tang D, Wang J, Qin Y, Liu Y, Tang C, et al: The mitochondria-targeted antioxidant MitoQ ameliorated tubular injury mediated by mitophagy in diabetic kidney disease via Nrf2/PINK1. Redox Biol 11: 297-311, 2017.

31. Dong ZW, Ren CG, Xia Y, Su D, Du TT, Fan HB, Yuan H, Wang L, Dong M, Li WC, et al: Pten regulates homeostasis and inflammation-induced migration of myelocytes in zebrafish. J Hematol Oncol 7: 17, 2014.

32. Zununi Vahed S, Barzegari A, Rahbar Saadat Y, Goreyshi A and Omidi Y: Leuconostoc mesenteroides-derived anticancer pharmaceuticals hinder inflammation and cell survival in colon cancer cells by modulating NF- $\kappa \mathrm{B} / \mathrm{AKT} / \mathrm{PTEN} / \mathrm{MAPK}$ pathways. Biomed Pharmacother 94: 1094-1100, 2017.

33. Yu S, Wang X, Geng P, Tang X, Xiang L, Lu X, Li J, Ruan Z, Chen J, Xie G, et al: Melatonin regulates PARP1 to control the senescence-associated secretory phenotype (SASP) in human fetal lung fibroblast cells. J Pineal Res 63, 2017.

34. Dufour F, Rattier T, Shirley S, Picarda G, Constantinescu AA, Morlé A, Zakaria AB, Marcion G, Causse S, Szegezdi E, et al: $\mathrm{N}$-glycosylation of mouse TRAIL-R and human TRAIL-R1 enhances TRAIL-induced death. Cell Death Differ 24: 500-510, 2017.

35. Xu S, Pi H, Zhang L, Zhang N, Li Y, Zhang H, Tang J, Li H, Feng M, Deng P, et al: Melatonin prevents abnormal mitochondrial dynamics resulting from the neurotoxicity of cadmium by blocking calcium-dependent translocation of Drp1 to the mitochondria. J Pineal Res 60: 291-302, 2016.

36. Alghanem AF, Wilkinson EL, Emmett MS, Aljasir MA, Holmes K, Rothermel BA, Simms VA, Heath VL and Cross MJ: RCAN1.4 regulates VEGFR-2 internalisation, cell polarity and migration in human microvascular endothelial cells. Angiogenesis 20: 341-358, 2017.

37. Glab JA, Doerflinger M, Nedeva C, Jose I, Mbogo GW, Paton JC, Paton AW, Kueh AJ, Herold MJ, Huang DC, et al: DR5 and caspase- 8 are dispensable in ER stress-induced apoptosis. Cell Death Differ 24: 944-950, 2017.

38. Zhu P, Hu S, Jin Q, Li D, Tian F, Toan S, Li Y, Zhou H and Chen Y: Ripk3 promotes ER stress-induced necroptosis in cardiac IR injury: A mechanism involving calcium overload/XO/ROS/mPTP pathway. Redox Biol 16: 157-168, 2018.

39. Han J, Weisbrod RM, Shao D, Watanabe Y, Yin X, Bachschmid MM, Seta F, Janssen-Heininger YMW, Matsui R, Zang M,et al: The redox mechanism for vascular barrier dysfunction associated with metabolic disorders: Glutathionylation of Rac1 in endothelial cells. Redox Biol 9: 306-319, 2016.

40. Zhou W, Yu L, Fan J, Wan B, Jiang T, Yin J, Huang Y, Li Q, Yin G and $\mathrm{Hu} \mathrm{Z}$ : Endogenous parathyroid hormone promotes fracture healing by increasing expression of BMPR2 through cAMP/PKA/CREB pathway in mice. Cell Physiol Biochem 42: 551-563, 2017

41. Iggena D, Winter Y and Steiner B: Melatonin restores hippocampal neural precursor cell proliferation and prevents cognitive deficits induced by jet lag simulation in adult mice. J Pineal Res 62, 2017.

42. Zhou H, Li D, Shi C, Xin T, Yang J, Zhou Y, Hu S, Tian F, Wang J and Chen Y: Effects of Exendin-4 on bone marrow mesenchymal stem cell proliferation, migration and apoptosis in vitro. Sci Rep 5: $12898,2015$.

43. Couto JA, Ayturk UM, Konczyk DJ, Goss JA, Huang AY, Hann S, Reeve JL, Liang MG, Bischoff J, Warman ML and Greene AK: A somatic GNA11 mutation is associated with extremity capillary malformation and overgrowth. Angiogenesis 20: 303-306, 2017.

44. Gao Y, Xiao X, Zhang C, Yu W, Guo W, Zhang Z, Li Z, Feng X, Hao J, Zhang K, et al: Melatonin synergizes the chemotherapeutic effect of 5-fluorouracil in colon cancer by suppressing PI3K/AKT and NF- $\mathrm{kB} / \mathrm{iNOS}$ signaling pathways. J Pineal Res 62, 2017.

45. Zhu H, Jin Q, Li Y, Ma Q, Wang J, Li D, Zhou H and Chen Y: Melatonin protected cardiac microvascular endothelial cells against oxidative stress injury via suppression of IP3R- $\left[\mathrm{Ca}^{2+}\right]$ c/VDAC- $\left[\mathrm{Ca}^{2+}\right] \mathrm{m}$ axis by activation of MAPK/ERK signaling pathway. Cell Stress Chaperones 23: 101-113, 2018.

46. Banerjee K, Keasey MP, Razskazovskiy V, Visavadiya NP, Jia C and Hagg T: Reduced FAK-STAT3 signaling contributes to ER stress-induced mitochondrial dysfunction and death in endothelial cells. Cell Signal 36: 154-162, 2017.

47. Garcia-Niño WR, Correa F, Rodriguez-Barrena JI, León-Contreras JC, Buelna-Chontal M, Soria-Castro E, Hernández-Pando R, Pedraza-Chaverri J and Zazueta C: Cardioprotective kinase signaling to subsarcolemmal and interfibrillar mitochondria is mediated by caveolar structures. Basic Res Cardiol 112: 15, 2017. 
48. Zhou H, Yang J, Xin T, Zhang T, Hu S, Zhou S, Chen G and Chen Y: Exendin- 4 enhances the migration of adipose-derived stem cells to neonatal rat ventricular cardiomyocyte-derived conditioned medium via the phosphoinositide 3-kinase/Akt-stroma cell-derived factor- $1 \alpha / \mathrm{CXC}$ chemokine receptor 4 pathway. Mol Med Rep 11: 4063-4072, 2015.

49. Zhou H, Hu S, Jin Q, Shi C, Zhang Y, Zhu P, Ma Q, Tian F and Chen Y: Mff-dependent mitochondrial fission contributes to the pathogenesis of cardiac microvasculature Ischemia/reperfusion injury via induction of mROS-mediated cardiolipin oxidation and $\mathrm{HK} 2 / \mathrm{VDAC} 1$ disassociation-involved $\mathrm{mPTP}$ opening. J Am Heart Assoc 6: pii: e005328, 2017.

50. Zhou H, Wang S, Zhu P, Hu S, Chen Y and Ren J: Empagliflozin rescues diabetic myocardial microvascular injury via AMPK-mediated inhibition of mitochondrial fission. Redox Biol 15: 335-346, 2018.

51. Murphy PS, Wang J, Bhagwat SP, Munger JC, Janssen WJ, Wright TW and Elliott MR: CD73 regulates anti-inflammatory signaling between apoptotic cells and endotoxin-conditioned tissue macrophages. Cell Death Differ 24: 559-570, 2017.

52. Kalyanaraman B: Teaching the basics of cancer metabolism: Developing antitumor strategies by exploiting the differences between normal and cancer cell metabolism. Redox Biol 12 : 833-842, 2017.

53. Das N, Mandala A, Naaz S, Giri S, Jain M, Bandyopadhyay D, Reiter RJ and Roy SS: Melatonin protects against lipid-induced mitochondrial dysfunction in hepatocytes and inhibits stellate cell activation during hepatic fibrosis in mice. J Pineal Res 62, 2017.

54. Yang HH, Chen Y, Gao CY, Cui ZT and Yao JM: Protective effects of MicroRNA-126 on human cardiac microvascular endothelial cells against hypoxia/reoxygenation-induced injury and inflammatory response by activating PI3K/Akt/eNOS signaling pathway. Cell Physiol Biochem 42: 506-518, 2017.

55. Sigala F, Efentakis P, Karageorgiadi D, Filis K, Zampas $P$, Iliodromitis EK, Zografos G, Papapetropoulos A and Andreadou I: Reciprocal regulation of eNOS, $\mathrm{H}_{2} \mathrm{~S}$ and $\mathrm{CO}$-synthesizing enzymes in human atheroma: Correlation with plaque stability and effects of simvastatin. Redox Biol 12: 70-81, 2017.

56. Xu J, Wu Y, Lu G, Xie S, Ma Z, Chen Z, Shen HM and Xia D Importance of ROS-mediated autophagy in determining apoptotic cell death induced by physapubescin B. Redox Biol 12 198-207, 2017

57. Hu SY, Zhang Y, Zhu PJ, Zhou H and Chen YD: Liraglutide directly protects cardiomyocytes against reperfusion injury possibly via modulation of intracellular calcium homeostasis. J Geriatr Cardiol 14: 57-66, 2017.

58. Liu Z, Gan L, Xu Y, Luo D, Ren Q, Wu S and Sun C: Melatonin alleviates inflammasome-induced pyroptosis through inhibiting NF- $\mathrm{B}$ /GSDMD signal in mice adipose tissue. J Pineal Res 63 2017.

59. Zhou H, Du W, Li Y, Shi C, Hu N, Ma S, Wang W and Ren J: Effects of melatonin on fatty liver disease: The role of NR4A1/DNA-PKcs/p53 pathway, mitochondrial fission, and mitophagy. J Pineal Res 64, 2018.

60. Jahandiez V, Cour M, Bochaton T, Abrial M, Loufouat J, Gharib A, Varennes A, Ovize M and Argaud L: Fast therapeutic hypothermia prevents post-cardiac arrest syndrome through cyclophilin D-mediated mitochondrial permeability transition inhibition. Basic Res Cardiol 112: 35, 2017.

61. Yang X, Wang H, Ni HM, Xiong A, Wang Z, Sesaki H, Ding WX and Yang L: Inhibition of Drp1 protects against senecionine-induced mitochondria-mediated apoptosis in primary hepatocytes and in mice. Redox Biol 12: 264-273, 2017.
62. Zhou H, Zhu P, Wang J, Zhu H, Ren J and Chen Y: Pathogenesis of cardiac ischemia reperfusion injury is associated with CK2 $\alpha$-disturbed mitochondrial homeostasis via suppression of FUNDC1-related mitophagy. Cell Death Differ 25: 1080-1093, 2018.

63. Zhou H, Wang J, Zhu P, Zhu H, Toan S, Hu S, Ren J and Chen Y: NR4A1 aggravates the cardiac microvascular ischemia reperfusion injury through suppressing FUNDC1-mediated mitophagy and promoting Mff-required mitochondrial fission by CK2 $\alpha$. Basic Res Cardiol 113: 23, 2018.

64. Zhou H, Shi C, Hu S, Zhu H, Ren J and Chen Y: BI1 is associated with microvascular protection in cardiac ischemia reperfusion injury via repressing Syk-Nox2-Drp1-mitochondrial fission pathways. Angiogenesis: Apr 6, 2018 (Epub ahead of print).

65. Zhou H, Li D, Zhu P, Ma Q, Toan S, Wang J, Hu S, Chen Y and Zhang Y: Inhibitory effect of melatonin on necroptosis via repressing the Ripk3-PGAM5-CypD-mPTP pathway attenuates cardiac microvascular ischemia reperfusion injury. J Pineal Res: e12503, 2018

66. Le Cras TD, Mobberley-Schuman PS, Broering M, Fei L, Trenor CC 3rd and Adams DM: Angiopoietins as serum biomarkers for lymphatic anomalies. Angiogenesis 20: 163-173, 2017.

67. Niaudet C, Bonnaud S, Guillonneau M, Gouard S, Gaugler MH, Dutoit S, Ripoche N, Dubois N, Trichet V, Corre I and Paris F: Plasma membrane reorganization links acid sphingomyelinase/ceramide to p38 MAPK pathways in endothelial cells apoptosis. Cell Signal 33: 10-21, 2017.

68. Li Q, Qi F, Meng X, Zhu C and Gao Y: Mst1 regulates colorectal cancer stress response via inhibiting Bnip3-related mitophagy by activation of JNK/p53 pathway. Cell Biol Toxicol: Oct 24, 2017 (Epub ahead of print).

69. Kumar A, Kunal S and Shah A: Frequency and effect of type 1 hypersensitivity in patients from India with chronic obstructive pulmonary disease and associated upper airways symptoms. Asia Pac Allergy 7: 199-205, 2017.

70. Hong H, Tao T, Chen S, Liang C, Qiu Y, Zhou Y and Zhang R: MicroRNA-143 promotes cardiac ischemia-mediated mitochondrial impairment by the inhibition of protein kinase Cepsilon. Basic Res Cardiol 112: 60, 2017.

71. Yang S, Zhang J, Wang S, Shi J and Zhao X: Knockdown of angiopoietin-like protein 2 ameliorates diabetic nephropathy by inhibiting TLR4. Cell Physiol Biochem 43: 685-696, 2017.

72. Deng W, Wang Y, Long X, Zhao R, Wang Z, Liu Z, Cao S and Shi B: miR-21 reduces hydrogen peroxide-induced apoptosis

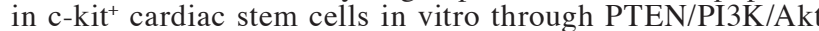
signaling. Oxid Med Cell Longev 2016: 5389181, 2016.

73. Wang Z, Li N, Wang B and Lin J: Nonalcoholic fatty liver disease progression in rats is accelerated by splenic regulation of liver PTEN/AKT. Saudi J Gastroenterol 21: 232-238, 2015.

74. Van Nostrand JL, Bowen ME, Vogel H, Barna M and Attardi LD: The 553 family members have distinct roles during mammalian embryonic development. Cell Death Differ 24: 575-579, 2017.

75. Ligeza J, Marona P, Gach N, Lipert B, Miekus K, Wilk W, Jaszczynski J, Stelmach A, Loboda A, Dulak J, et al: MCPIP1 contributes to clear cell renal cell carcinomas development. Angiogenesis 20: 325-340, 2017.

76. Zhou H, Ma Q, Zhu P, Ren J, Reiter RJ and Chen Y: Protective role of melatonin in cardiac ischemia-reperfusion injury: From pathogenesis to targeted therapy. J Pineal Res 64, 2018.

77. Zhou H, Wang J, Zhu P, Hu S and Ren J: Ripk3 regulates cardiac microvascular reperfusion injury: The role of IP3R-dependent calcium overload, XO-mediated oxidative stress and F-action/filopodia-based cellular migration. Cell Signal 45: 12-22, 2018. 